Natural Hazards and Earth System Sciences, 5, 633-648, 2005

SRef-ID: 1684-9981/nhess/2005-5-633

European Geosciences Union

(C) 2005 Author(s). This work is licensed

under a Creative Commons License.

\title{
Emerging insights into the dynamics of submarine debris flows
}

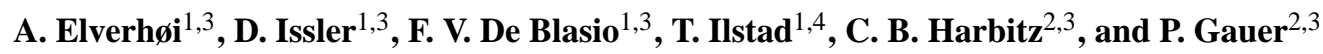 \\ ${ }^{1}$ Dept. of Geosciences, University of Oslo, P.O. Box 1047 Blindern, 0316 Oslo, Norway \\ ${ }^{2}$ Norwegian Geotechnical Institute, P.O. Box 3930 Ullevål Stadion, 0806 Oslo, Norway \\ ${ }^{3}$ International Centre for Geohazards, c/o NGI, P.O. Box 3930 Ullevål Stadion, 0806 Oslo, Norway \\ ${ }^{4}$ Present address: Reinertsen Engineering AS, Leiv Eiriksson Senter, 7492 Trondheim, Norway \\ Received: 21 March 2005 - Revised: 19 July 2005 - Accepted: 19 July 2005 - Published: 17 August 2005 \\ Part of Special Issue "Tsunami hazard from slope instability"
}

\begin{abstract}
Recent experimental and theoretical work on the dynamics of submarine debris flows is summarized. Hydroplaning was first discovered in laboratory flows and later shown to likely occur in natural debris flows as well. It is a prime mechanism for explaining the extremely long runout distances observed in some natural debris flows even of overconsolidated clay materials. Moreover, the accelerations and high velocities reached by the flow head in a short time appear to fit well with the required initial conditions of observed tsunamis as obtained from back-calculations. Investigations of high-speed video recordings of laboratory debris flows were combined with measurements of total and pore pressure. The results are pointing towards yet another important role of ambient water: Water that intrudes from the water cushion underneath the hydroplaning head and through cracks in the upper surface of the debris flow may drastically soften initially stiff clayey material in the "neck" of the flow, where significant stretching occurs due to the reduced friction at the bottom of the hydroplaning head. This selfreinforcing process may lead to the head separating from the main body and becoming an "outrunner" block as clearly observed in several natural debris flows. Comparison of laboratory flows with different material composition indicates a gradual transition from hydroplaning plug flows of stiff clayrich material, with a very low suspension rate, to the strongly agitated flow of sandy materials that develop a pronounced turbidity current.
\end{abstract}

Statistical analysis of the great number of distinguishable lobes in the Storegga slide complex reveals power-law scaling behavior of the runout distance with the release mass over many orders of magnitude. Mathematical flow models based on viscoplastic material behavior (e.g. BING) successfully reproduce the observed scaling behavior only for relatively small clay-rich debris flows while granular (frictional) models fail at all scales. For very large release masses, hydroplaning or significant softening of the shear layer due to water in-

Correspondence to: A. Elverhøi

(anders.elverhoi@geo.uio.no) corporation must be invoked to recover the observed scaling behavior; a combination of both effects likely will give the most realistic description of the phenomenon. Detailed studies of the neck behavior and the compositional dependence of the material properties are needed to arrive at a quantitative model. Other related and important open questions concern the rheological model appropriate for sandy debris flows and the suspension rate from the dense body into the associated turbidity current.

\section{Introduction}

For many decades following the pioneering papers by Kuenen (1937); Kuenen and Migliorini (1950) and Heezen and Ewing (1952), turbidity currents have been at the focus of geologists' research on large-scale sediment transport in the oceans. However, quite early the experimental work of Hampton $(1970,1972)$ showed convincingly that submarine debris flows have the potential for transporting large sediment masses over considerable distances and might play a more important role in generating turbidity currents than had hitherto been recognized. In the meantime, the intensified search for deep-water hydrocarbon reservoirs with vastly improved surveying techniques has brought to light many large to very large debris flows deposits (Hühnerbach et al., 2004), with displaced sediment volume of roughly $2500 \mathrm{~km}^{3}$ in the case of the giant Storegga slide off the western Norwegian coast (Bugge et al., 1987; Haflidason et al., 2004). Moreover, many cases have been found where the runout ratio (defined as the vertical fall height divided by the horizontal runout distance) is on the order of $r \sim 0.01$ or less (Hampton et al., 1996; Elverhøi et al., 2002). Rather low runout ratios and significant size effects are also known for all other gravity mass flows, but in subaqueous debris flows $r$ is even lower than in all subaerial flows ( $r \geq 0.03$ according to Dade and Huppert, 1998, Fig. 1) and the dependence of $r$ on the release volume appears to be different (Elverhøi et al., 2002). It appears fair to say that submarine debris flows have been established 


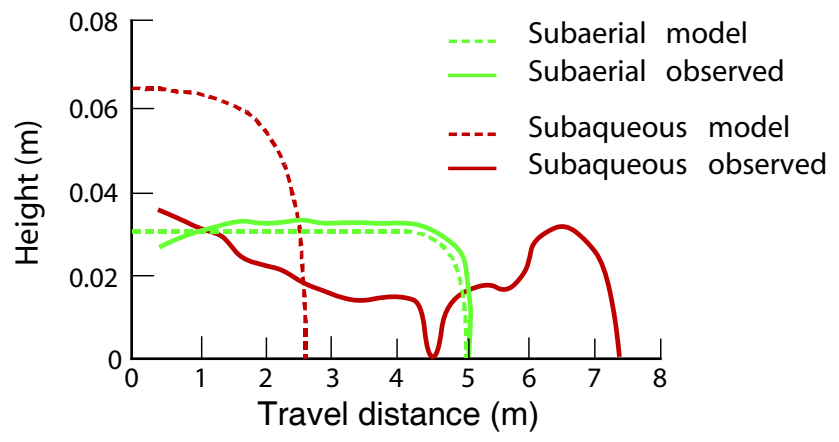

Fig. 1. Simulation results vs. measurements of subaerial and subaqueous laboratory debris flows. Experimental data are from Fig. 3 in (Mohrig et al., 1999), the simulation results from Fig. 5a of (Huang and García, 1999). The experimental settings were the same as in our experiments, except for a slope break from $6^{\circ}$ to $1^{\circ}$ at $5.7 \mathrm{~m}$. The slurry consisted of about $40 \mathrm{wt}$. $\%$ water, $24 \mathrm{wt} . \%$ kaolin, $24 \mathrm{wt}$ \% silt and $12 \mathrm{wt} . \%$ silica sand. The numerical simulations did not take into account hydroplaning or hydrodynamic drag.

as one of the most important agents for mass wasting at the continental margins of all oceans.

Astonishingly little research has since been directed at elucidating the differences between subaerial and submarine debris flows and in particular the effect that the ambient water has on the flow evolution. The key enigma connected to these flows - the extremely low runout ratio - is highlighted by Huang and García $(1998,1999)$ who applied a viscoplastic model to subaerial and subaqueous laboratory debris flows of the same initial composition. They achieved very good agreement between measured and predicted runout distances and deposit distributions in the subaerial case, but the model failed completely for subaqueous flows (Fig. 1). Against all considerations of increased buoyancy and drag forces in water, runout distances were observed to be significantly longer than in air (Mohrig et al., 1998, 1999). These experiments revealed that "hydroplaning" may occur in clay-rich subaqueous debris flows. Due to the combined action of stagnation pressure at the snout and dynamic underpressure above the head (Hampton, 1972), the debris-flow front is no longer capable of maintaining contact with the bed beyond a threshold velocity that is primarily determined by the flow thickness and the submerged density. A thin layer of water penetrates underneath the head and lubricates it. Not only were the runout distances of hydroplaning flows much longer than in the corresponding subaerial case, but also erosion of antecedent deposits was absent or insignificant (Mohrig et al., 1999). Other outstanding tasks are to characterize the flow behavior of debris flows in function of their compositional dependence and to quantify the evolution of the turbidity currents that are generated by debris flows (for a first attempt see (Mohrig and Marr, 2003)).

Our approach to these problems combines (i) detailed laboratory studies of fundamental mechanisms in subaqueous debris flows, (ii) analysis and interpretation of the scal- ing behavior of a well-characterized set of debris flows in a homogeneous setting, and (iii) numerical simulation of the overall flow dynamics with one-dimensional thicknessintegrated models and of specific aspects with more detailed two-dimensional models. In order to study the composition dependence of subaqueous debris flow dynamics, a series of experiments (Ilstad et al., 2004a,b,c) were conducted in the same tank as those by Mohrig et al. $(1998,1999)$; Mohrig and Marr (2003). Through the simultaneous measurement of the front velocity, the total and pore pressure at the bed, the internal velocity profile and the deposition rate, the flow regime could be determined for compositions ranging from clay-rich to very sandy. In particular the pressure measurements confirmed our inferences on the dynamics. We describe the most important results and discuss the overall picture of debrisflow dynamics as a function of the sediment composition in Sect. 2.

In complex flows like these, scaling the laboratory results to a huge natural event such as Storegga is an uncertain task. There are more than twelve orders of magnitude to bridge in the mass, five in the runout distance, four in the flow thickness, three in the fall height, and zero to three orders of magnitude in the sediment strength. Indirect evidence for the occurrence of certain flow mechanisms can be gained by studying the correlation between, e.g. the runout ratio $r$ and the release volume for a number of slides of different size but similar composition and topographic setting (Issler et al., 2003) and back-calculation with candidate models (Issler et al., 2005). This work is summarized in Sect. 3, whereas Sect. 4 shows how simple extensions of a basic viscoplastic model reproduce many important aspects of clay-rich debris flows (De Blasio et al., 2004a). Quite detailed two or threedimensional modeling of slab fracturing in the starting phase and of frontal behavior is also possible (Gauer et al., 2005), but requires a large numerical effort (Sect. 4.3). In Sect. 5 we indicate which problems need further study.

There are two interesting and practically important issues connected to our topic that we will only mention in passing, namely (i) the progressive transformation of (sand-rich) debris flows into turbidity currents and (ii) the tsunamigenic potential of debris flows - a problem that is presently being addressed by many research groups. Concerning the first issue, there seems to be a consensus that many turbidity currents are generated by debris flows, yet very little work has been done to quantify this process (Mohrig and Marr, 2003) and to understand and model the downstream variation of deposit composition (Drago, 2002; Tinterri et al., 2003). Laboratory experiments with sand-rich sediment mixtures combining the experimental techniques of Mohrig and Marr (2003) with those described here should be very fruitful for understanding the relevant processes in turbidity-current formation and for scaling the results from the laboratory to the continental margin. 


\section{Laboratory experiments}

Direct and detailed observation of submarine debris flows has not been possible because of the infrequent occurrence of such events at a fixed instrumented location and the huge forces that would act on traditional measurement devices. Flume experiments allow one to gain a great deal of insight into the flow regimes and basic mechanisms at work in those flows, but these results have to be assessed very critically with regard to their applicability to natural submarine debris flows. In this section, we describe the experiments carried out in flumes at the St. Anthony Falls Laboratory, University of Minnesota in Minneapolis, and postpone the thorny similarity issue to Sect. 5 .

\subsection{Setup, materials and procedures}

In all experiments, premixed and stirred slurry was released into a flume by rapidly opening a gate. For the most detailed measurements, a quasi-two-dimensional setting was used, with a $9 \mathrm{~m}$ long and $0.2 \mathrm{~m}$ wide channel with a rough bed, submerged in a large water tank at an inclination of $6^{\circ}$, see Fig. 2. The released slurry mass was $0.16 \mathrm{~m}^{3}$. Measurement devices included the following (Ilstad et al., 2004b,c): (1) Two pairs of pressure transducers, located at $3.5 \mathrm{~m}$ and $7.6 \mathrm{~m}$ from the gate and measuring the pore pressure and the total normal stress at the bed. (2) A normal video camera was moved on a rail parallel to the flow front. (3) A high speed video camera, placed $3.5 \mathrm{~m}$ from the gate, recorded the flow from the side at 250 frames per second, with sufficient resolution for small tracer particles (coal slag) to be identified. (4) A normal video camera recorded the flow at 30 frames per second from the side at the location of the lower pair of pressure sensors.

In order to study the lateral spreading of the debris flows and their frontal behavior in a laterally unconfined setting, another set of experiments was run on a $2.25 \mathrm{~m}$ wide and $9 \mathrm{~m}$ long plane, inclined at $8^{\circ}$ inside a much longer channel. The flows were recorded with several normal-speed video cameras, and the deposits were photographed (Ilstad et al., 2004a). Here, $0.4 \mathrm{~m}^{3}$ of slurry were used.

The slurries used in the unconfined flows all had the same composition with $35 \mathrm{wt} . \%$ water, $35 \mathrm{wt} . \%$ sand and $30 \mathrm{wt} . \%$ kaolinite clay and a remoulded shear strength of approximately $150 \mathrm{~Pa}$. In the narrow channel, the water content was also fixed at $35 \mathrm{wt} . \%$, but the kaolin content was varied from 5 to $32.5 \mathrm{wt} . \%$, producing slurries from very sandy to clayrich. Rheological measurements with a vane in a cup were performed on completely remoulded slurry sampled before each run. All samples exhibited a yield strength and shear thinning, which was most pronounced in the most clay-rich specimens, and the yield strength was found to grow exponentially with clay content (Ilstad et al., 2004b).

With the help of the moving video camera, the evolution of the front speed could be determined easily and accurately. Also, qualitative information on the deformation of the head, the formation of a turbidity current - due to the stresses ex-

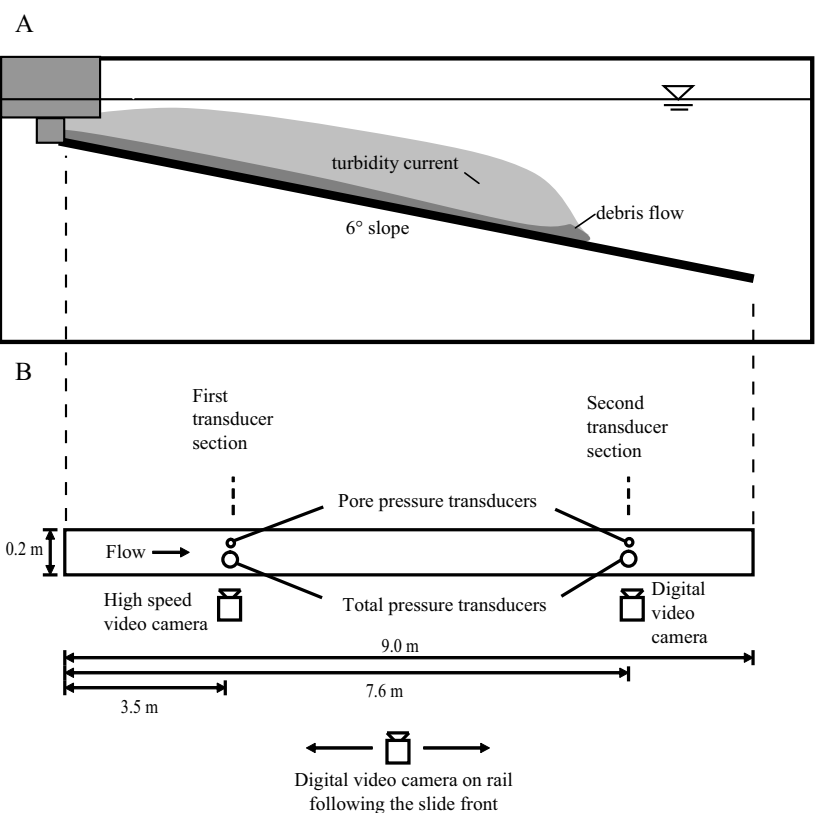

Fig. 2. Schematic view of laboratory setup, showing the location of the pressure sensors and video cameras. Adapted from (Ilstad et al., 2004b).

erted by the recirculating ambient water - and the intrusion of a thin water layer underneath the head was gained. The visual observations of the interface between the bed and the flow at the head and at the fixed camera locations could be confronted with the combined measurements of the total bednormal load and the pore pressure at the same fixed locations. As will be discussed in Sect. 4.2, a consistent picture of relevance for explaining the enhanced runout distances of subaqueous debris flows emerges from these measurements.

A simple computer-assisted method for tracking particles near the side wall from the high-speed video recordings was developed (Ilstad et al., 2004b). At a frame rate of $250 \mathrm{~s}^{-1}$ and flow velocities up to $1 \mathrm{~m} \mathrm{~s}^{-1}$, dark tracer particles (coal slag) had to be mixed into the slurry in low concentration to enable identification of the same particles on subsequent images. As this analysis is very time-consuming, only three selected short intervals of nearly steady flow during the passage of the head, body and tail have so far been analyzed in this way for the different slurry compositions. From the recorded particle trajectories, we determined the corresponding horizontal and vertical velocities between sequential images, separately for each of 16 horizontal slices. This allowed us to compute the vertical profiles of the mean and standard deviation of the horizontal and vertical velocity.

\subsection{Compositional dependence of flow behavior}

In the terminology of Marr et al. (2001), the clay-rich slurries (with $25 \mathrm{wt} . \%$ of kaolinite clay or more) produced strongly coherent flows. This means that the body of the flow remained dense and underwent no or limited shear; virtually 


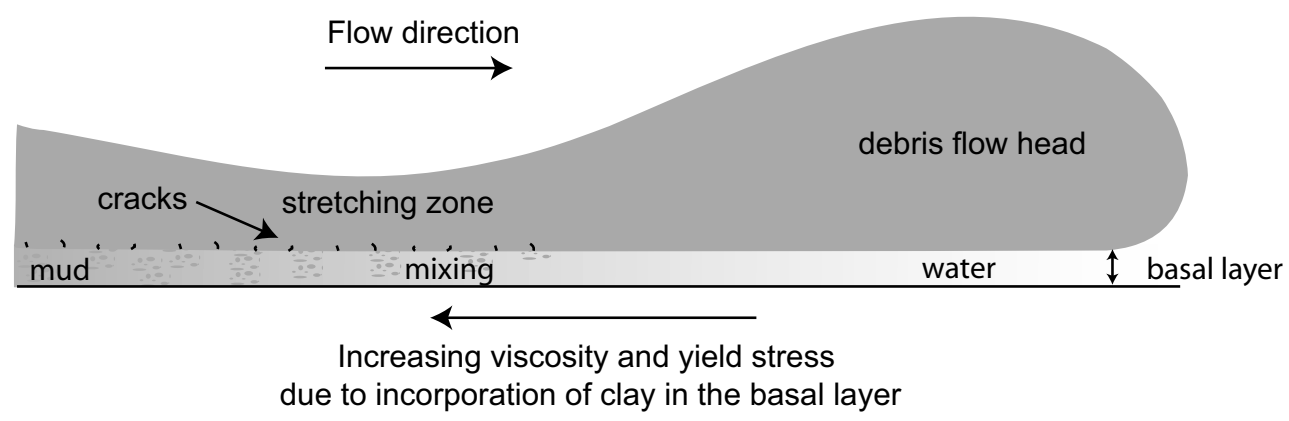

2nd time interval

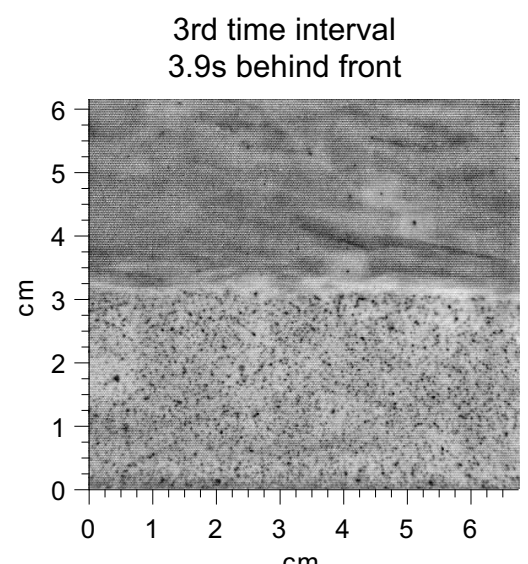

$2.1 \mathrm{~s}$ behind front
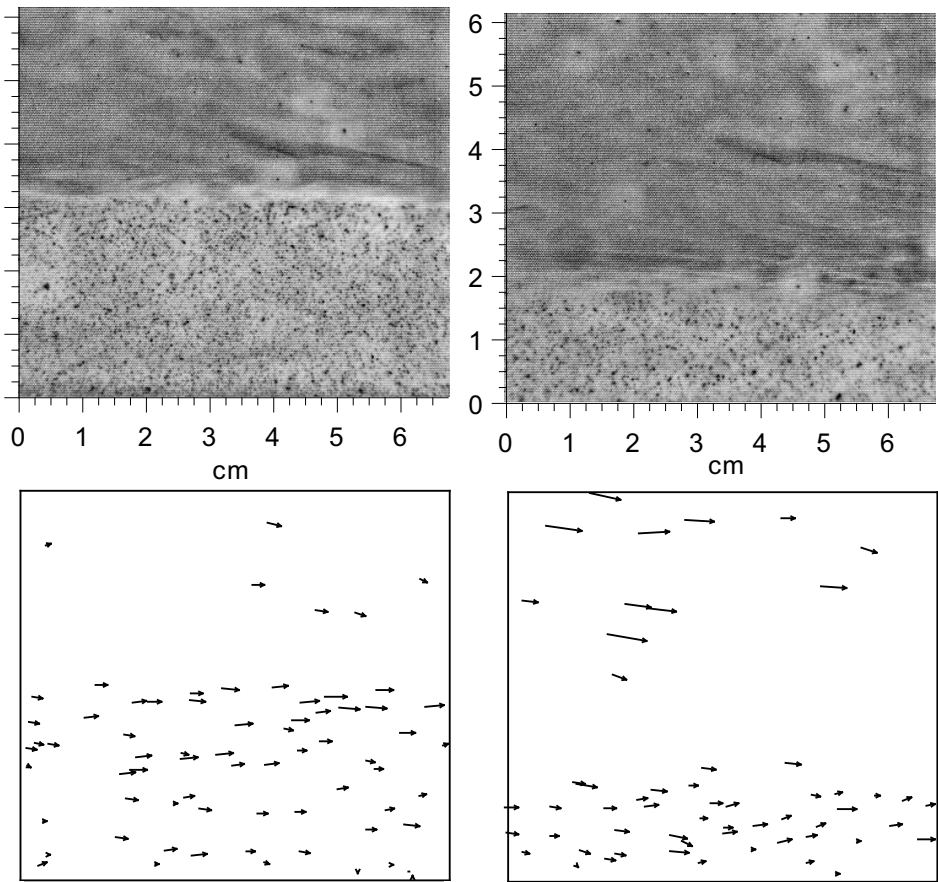

$\begin{array}{lll}-0.25 & 0 & 0.25\end{array}$

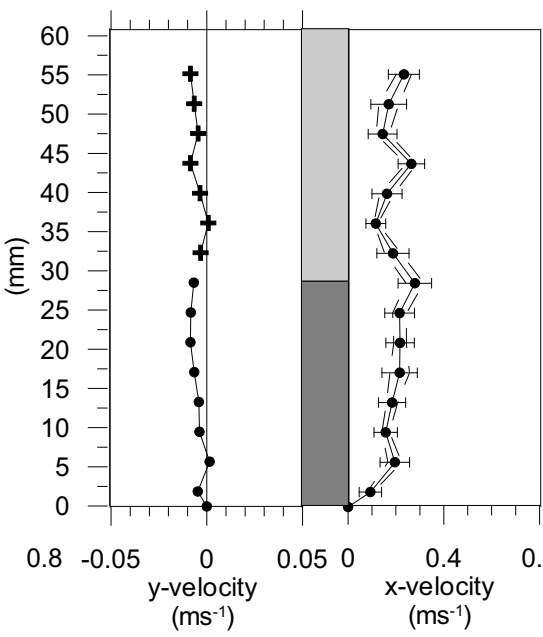

Water layer

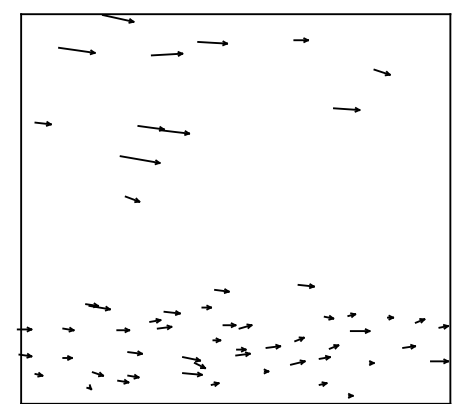

$\begin{array}{lll}-0.25 & 0 & 0.25\end{array}$

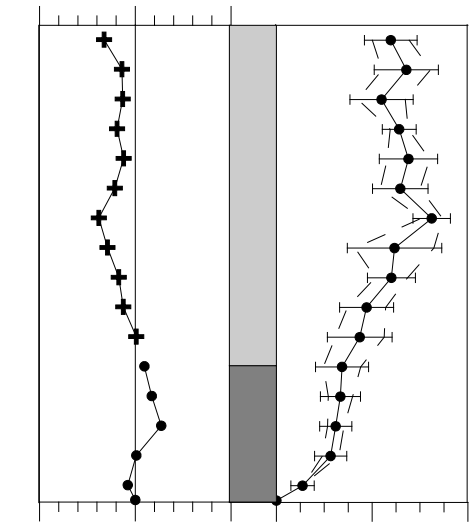
$0.8-0.05 \underset{\text { y-velocity }}{0} 0.050$
$\left(\mathrm{ms}^{-1}\right)$ $\mathrm{x}$-velocity $\left(\mathrm{ms}^{-1}\right)$

Dense flow 1st time interval

$0.37 \mathrm{~s}$ behind front
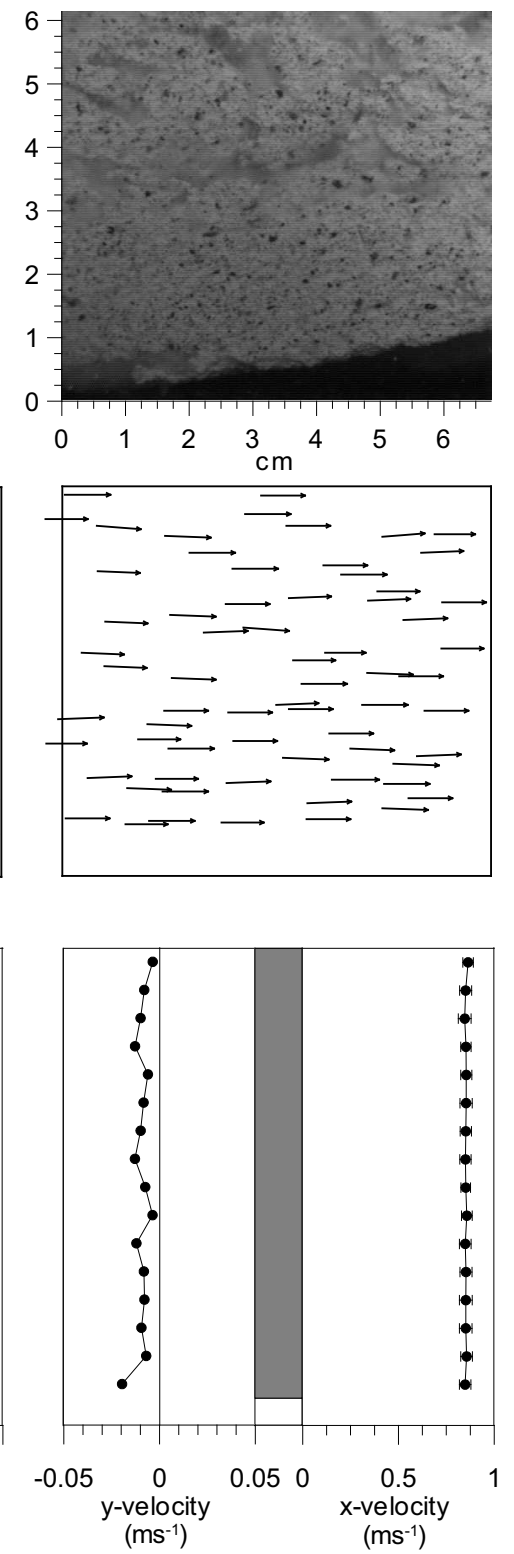

Turbidity current

Fig. 3. Schematic representation of head-neck-body structure of clay-rich debris flow ( 35 wt. $\%$ water, 36.3 wt. $\%$ sand, 28.7 wt. $\%$ kaolinite clay) with hydroplaning head, slow body and stretching neck (top). The side views (second row), instantaneous velocity vectors (third row), and profiles of vertical and horizontal velocity (bottom) are shown underneath their approximate locations in the flow. The head hydroplanes as a rigid block on top of a thin, but clearly visible water cushion. It is somewhat deformed by the drag forces, but sheds only small quantities of particles into suspension. Such flows are termed strongly coherent. Note that the vertical velocities in the dense flow are scaled five-fold relative to those in the turbidity current. Figure adapted from (Ilstad et al., 2004b). 

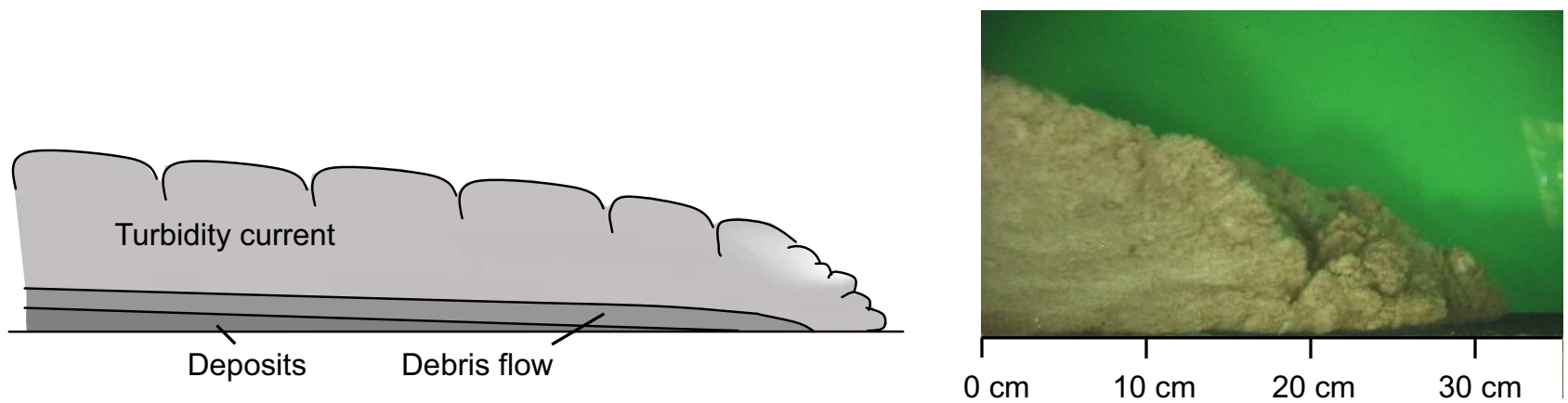

3rd time interval

$6.1 \mathrm{~s}$ behind front

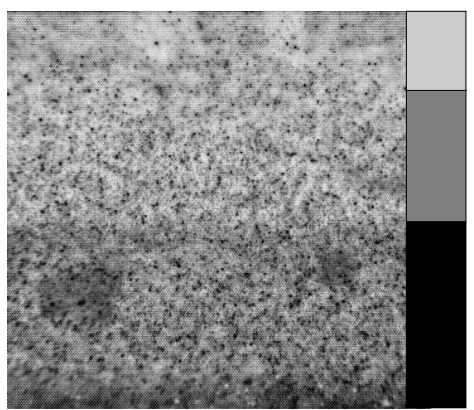

2nd time interval

$3.8 \mathrm{~s}$ behind front

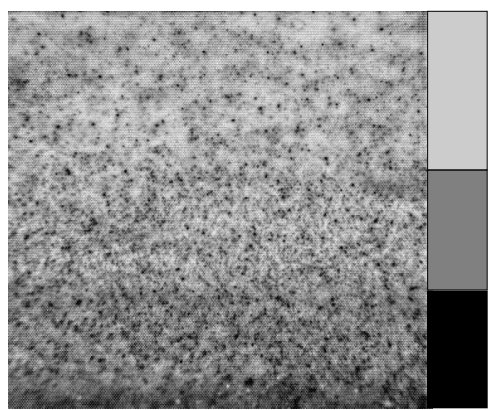

1st time interval

$1.4 \mathrm{~s}$ behind front

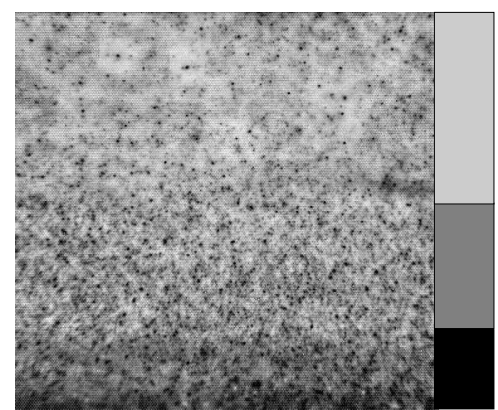

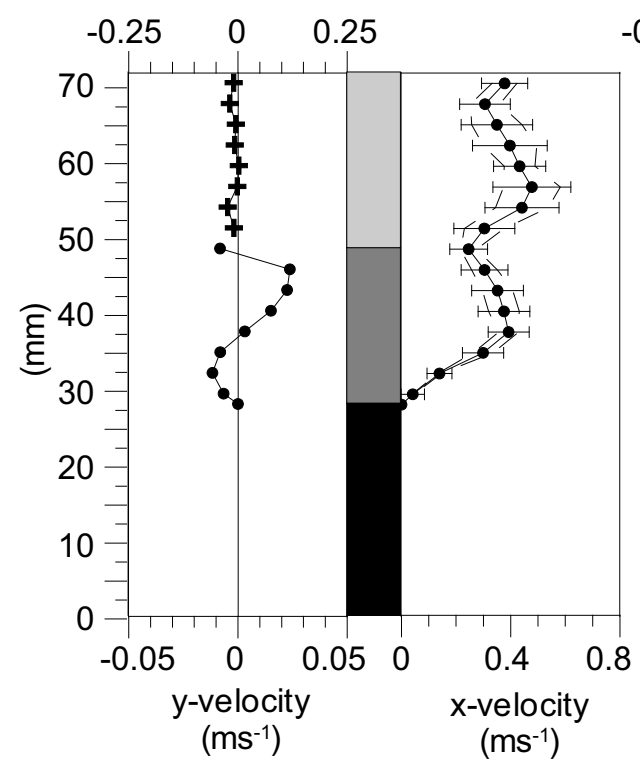

Deposition $\begin{array}{lll}-0.25 & 0 & 0.25\end{array}$

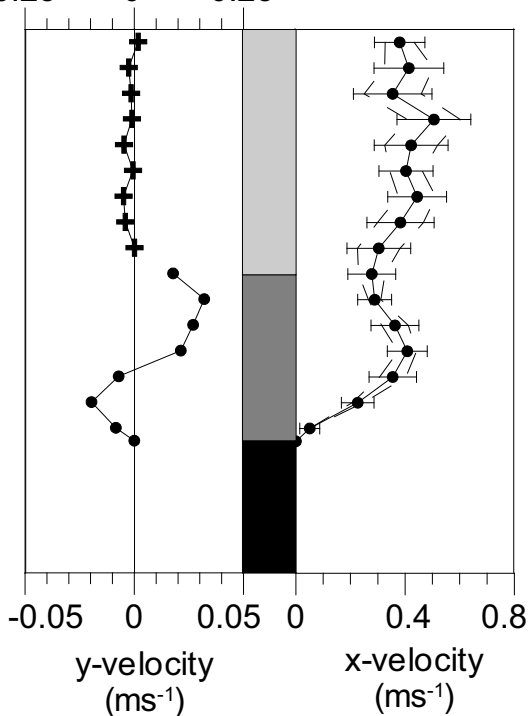

$\begin{array}{lll}-0.25 & 0 & 0.25\end{array}$

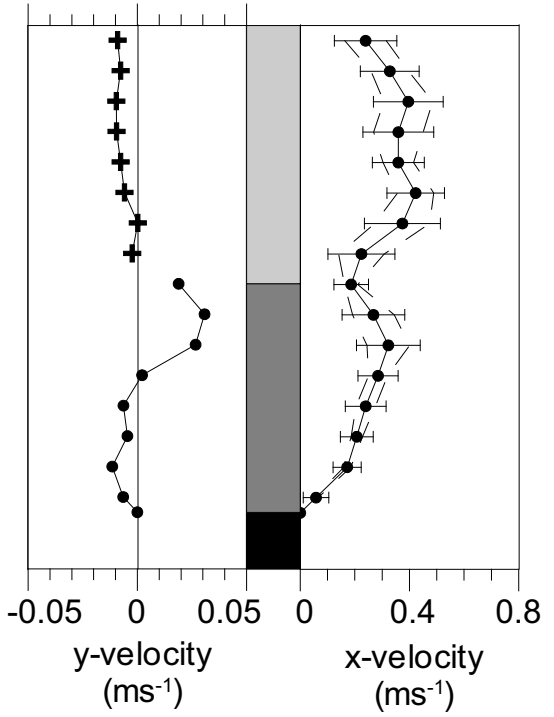

Turbidity current

Fig. 4. Side-views (top) and profiles of vertical and horizontal velocity (bottom) of a sandy debris flow in the laboratory (35 wt. $\%$ water, 60 wt. \% sand, 5 wt. \% kaolinite clay). As in Fig. 3, snapshots are from the head (right), neck (middle) and tail regions (left) and the $y$-velocity scale differs for the dense and turbidity layers. Note the turbulent structure of the head and the high rate of particle suspension. Such flows are termed weakly coherent by Marr et al. (2001). Adapted from Figs. 6 and 8 of (Ilstad et al., 2004b).

no deposition took place and suspension from the front and top of the flow was weak. The head moved as a rigid block detached from the bed whereas the neck and the body featured a shear layer about 5-10 mm deep underneath a layer with little mean shear but still measurable velocity fluctua- tions (see Fig. 3). There is not enough analyzed data yet to draw firm conclusions, but rather abrupt changes of the shear rate in a number of velocity profiles may hint at corresponding changes of the material properties occurring at the interface between the shear and plug layer. 
In contrast, the slurries with 5 and $10 \mathrm{wt} \%$ of kaolinite clay (Fig. 4) produced weakly coherent flows, with significant quantities of water penetrating into the head and developing a turbulent vortical structure. Substantial shear was also observed throughout the body of the flow. At $5 \mathrm{wt}$. \% clay, no plug layer was seen anywhere in the flow. At $10 \mathrm{wt}$. \% clay, the mean velocity profile would be interpreted as featuring a plug layer, but the velocity fluctuations are very strong (around $50 \%$ of the mean flow velocity). Both deposition of sand from the body and suspension of clayey material from the head were very pronounced. At $3.5 \mathrm{~m}$ from the gate, deposition rates were almost identical for 10 and $15 \mathrm{wt}$. \% clay and two to three times smaller than for $5 \mathrm{wt} . \%$ clay. (Note that sedimentation measurements at a single point like ours have to be interpreted with care because the sediment composition may change significantly along the flow in response to upstream sedimentation.)

Between the extremes of less than $10 \mathrm{wt} . \%$ and more than 25 wt. $\%$ of clay, a gradual transition was observed. The flows from slurries with 15 and $20 \mathrm{wt}$ \% of clay are to be characterized as moderately coherent flows. A shear layer existed all along the flows, with a weakly sheared but fluctuating layer flowing on top of it, and the formation rate of the turbidity current was moderate. Plug flow was observed only in the heads of the most clay-rich flows. Somewhat surprisingly, the deposition rate at $15 \mathrm{wt} . \%$ clay was equal or slightly larger than at $10 \mathrm{wt} . \%$, whereas no deposition was observed at $20 \mathrm{wt} . \%$ except in the tail.

Our experiments fully confirm the results obtained by Marr et al. (2001) and Mohrig and Marr (2003). They do not span the entire parameter space of laboratory debris flows since the water concentration in the slurry, the initial mass and the slope angle were the same in all runs. As noted by Mohrig and Marr (2003), water content has a strong influence on flow behavior in that large particles will rapidly settle out if inter-particle distances are large and the clay content is not high. Nevertheless, the flow properties changed quite smoothly from one clay concentration level to the next. It thus appears unlikely that a search over a wider parameter range would reveal abrupt flow-regime changes as a function of composition.

\subsection{Hydroplaning heads in clay-rich debris flows}

In the strongly coherent flows with $25 \mathrm{wt}$ \% clay or more, a thin wedge-shaped water layer was clearly visible underneath the head, unequivocally signaling hydroplaning. No such layer was observed in any of the flows with $20 \mathrm{wt}$ \% clay or less. The length of the layer was up to ten times the height of the head. Mohrig et al. (1998) determined the densimetric Froude number for initiation of hydroplaning as $\mathrm{Fr}_{d} \approx 0.3-0.4^{1}$. From the balance of gravitational and pressure forces (the latter being positive at the front and under-

\footnotetext{
${ }^{1}$ The densimetric Froude number takes into account buoyancy effects and is defined as $\operatorname{Fr}_{d}=U(\tilde{g} \cos \theta)^{-1 / 2}$, where $\tilde{g}=g\left(\rho_{d}-\rho_{w}\right) / \rho_{d} ; g$ is the gravitational acceleration, $\rho_{d}$ the density of the debris and $\rho_{w}$ the density of the ambient water.
}

neath the flowing material, but negative on the upper surface of the flow), one sees that the threshold Froude number will depend somewhat on the shape of the head, but will be close to the value found in the laboratory flows even for large natural debris flows. Simple estimates as well as model simulations (Mohrig et al., 1998; Harbitz et al., 2003; De Blasio et al., 2004b) indicate that many large natural submarine debris flows should attain sufficient velocities quite soon after release. It is therefore very likely that hydroplaning is an important mechanism for explaining very long runout distances in strongly coherent debris flows, especially for outrunner blocks.

The videos following the front show that the front velocity remains nearly constant near $1 \mathrm{~m} \mathrm{~s}^{-1}$ in the case of sand-rich slurries while it diminishes gradually but slowly in clay-rich flows after the short phase of rapid initial acceleration. Analysis of the high-speed video recordings confirmed these values of the front velocity and also revealed that the velocity is much smaller (on the order of $0.3-0.5 \mathrm{~m} \mathrm{~s}^{-1}$ ) behind the head. The flow thickness also diminishes significantly there, forming a "neck" of growing length, behind which the flow thickness is larger (but clearly less than in the head).

The pore and total pressure measurements reported by Ilstad et al. (2004c) reveal that the pore pressure at the bed supports essentially the entire weight of the head in all of our runs, be they hydroplaning or not, while it is clearly less than the overburden in the rear part of all flows. However, there are characteristic differences with respect to the pressure fluctuations. Where visual observations indicated hydroplaning flow, the pressure fluctuations were weak and of relatively low frequency. In contrast, the turbulent head that formed in weakly coherent flows manifested itself in strong, high-frequency pressure fluctuations. We note in passing that the pore pressure decayed within 1 to $2 \mathrm{~min}$ in the weakly coherent flows after they had stopped, but persisted for more than $15 \mathrm{~min}$ in strongly coherent flows.

\subsection{Stretching as a consequence of hydroplaning}

The large velocity difference between the head and the tail of the flow implies a very significant amount of stretching, the strain rate in the flow direction, $\partial_{s} u_{s}$, being of the order of $1-$ $5 \mathrm{~s}^{-1}$. By mass conservation, stretching in the longitudinal direction must be accompanied by constriction in the bednormal and possibly also the spanwise direction (as long as the flowing body does not fracture). Indeed, only bed-normal constriction was observed in the narrow channel (confined experiments) and both modes in the wide channel (unconfined experiments). The flow region with little shear is thus a zone of extensional flow where the internal structure of the material is continually rearranged to a large degree. We conjecture that this is achieved by means of small local fractures. This may explain the strong velocity fluctuations observed in the strongly coherent flows behind the hydroplaning head.

Further evidence for the important role of stretching in the overall dynamics is provided by a comparison of the measured flow-layer thicknesses and the yield strength of the 
original slurry. Based on the criterion that the flow thickness must be larger than the plug layer thickness, our laboratory flows should have stopped much earlier. This indicates that the yield strength decreased during flow, either in the entire slurry or - more likely - in the strongly sheared basal layer. Since the slurry was fully remoulded from the start, further weakening must be due to the incorporation of water. We conjecture that cracks that form throughout the entire flow thickness due to stretching and also in the bottom layer due to shear serve as the "entrance ports" for the water. We coined the term "shear-wetting" for this process in order to clearly distinguish it from (undrained) remoulding where the water content remains constant (perhaps "strain-induced wetting" would be more precise.).

Combining the observations on the behavior of the front with simple mechanical considerations, the following picture emerges. The stagnation pressure at the snout of the flow and the underpressure along the top of the head lead to the intrusion of a wedge-shaped water layer underneath the head and the onset of hydroplaning in the case of clay-rich flows, or to turbulent mixing along the head surface in the case of sandy flows. In both cases, the head experiences reduced frictional forces, but not the main body of the flow. Hence the head accelerates and moves away from the body. A neck forms that becomes progressively thinner; with the reduced cross-section, the tensile stresses increase. Furthermore, the stretching also leads to the formation of cracks through which ambient water can penetrate, leading to additional local softening of the material. Under certain conditions (which we cannot determine yet), the head may detach completely (auto-acephalation) from the body and form an outrunner block.

\section{Scaling behavior in the Storegga slide complex}

\subsection{The importance of Storegga as a "natural laboratory"}

The Storegga slide complex, situated off the western Norwegian coast (see Fig. 5), is one of the largest known landslides on Earth, with a total of approximately $2500 \mathrm{~km}^{3}$ of seafloor released about 8000 years B.P. The runout distance of the debris flow exceeded $400 \mathrm{~km}$ and the turbidites extend to $800 \mathrm{~km}$ from the source area (Bugge, 1983; Bugge et al., 1987). Plans for exploiting the Ormen Lange gas field, located near the foot of the very steep present-day headwall, triggered a geological and geotechnical investigation of unprecedented scope and depth. Among the many remarkable results was the recognition of more than 60 distinct lobes, based on geomorphological interpretation combined with analysis of seismic profiles (Haflidason et al., 2004). In Fig. 5, the five earliest and largest phases are indicated; seven further phases with progressively smaller slides have been identified. The runout distances and volumes of these lobes span several orders of magnitude as a result of the retrogressive nature of the slide evolution; it is crucial, however, that

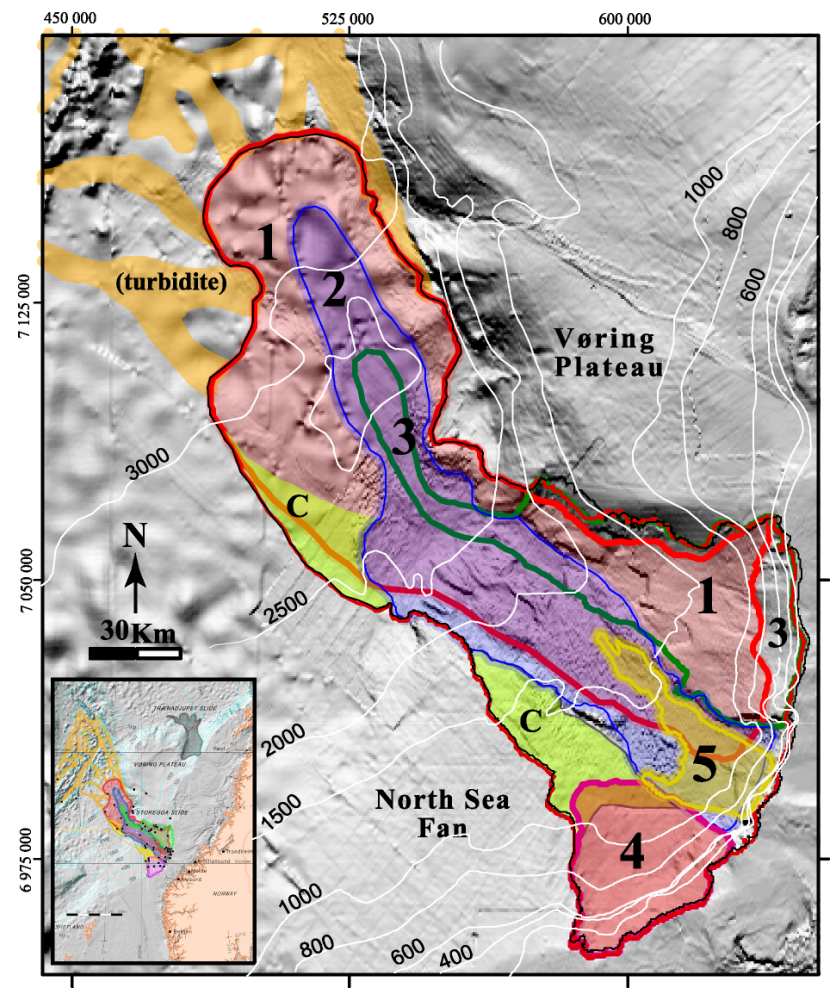

Fig. 5. Overview map of the Storegga slide complex, showing the deposit areas of the different main phases of the debris flow. The location of the site and the extension of the turbidity current can be seen from the inset. This map was kindly adapted by $\mathrm{H}$. Haflidason from Fig. 12A of (Haflidason et al., 2004).

they all consist of nearly identical material, namely normally consolidated to overconsolidated clays.

3.2 Power-law scalings of the runout distance with the release mass

These circumstances suggest that statistical analysis of the relationship between the runout distance $R$ or the runout ratio $r \equiv H / R$ (where $H$ is the drop height) and the released mass may give clues as to the rheology of the flowing material at least for the case of the Storegga slide. Indeed, power-law relations with remarkably low scatter are found (Issler et al., 2005) for certain geometrical properties of the released slabs as well as for $R$ and $r$ (Fig. 6):

$$
\begin{aligned}
R & =31.1 \mathrm{~km}^{-0.78} \cdot A^{0.89}, \\
r & =0.022 \mathrm{~km}^{1.04} \cdot A^{-0.52} .
\end{aligned}
$$

$A$ is the release volume per unit width or the mean area of all longitudinal sections through the release area. For slides whose width is a substantial fraction of their runout distance and which approximately maintain their width over the entire flow distance, this is a more relevant quantity for the dynamics than the release volume. Moreover, the Storegga release 

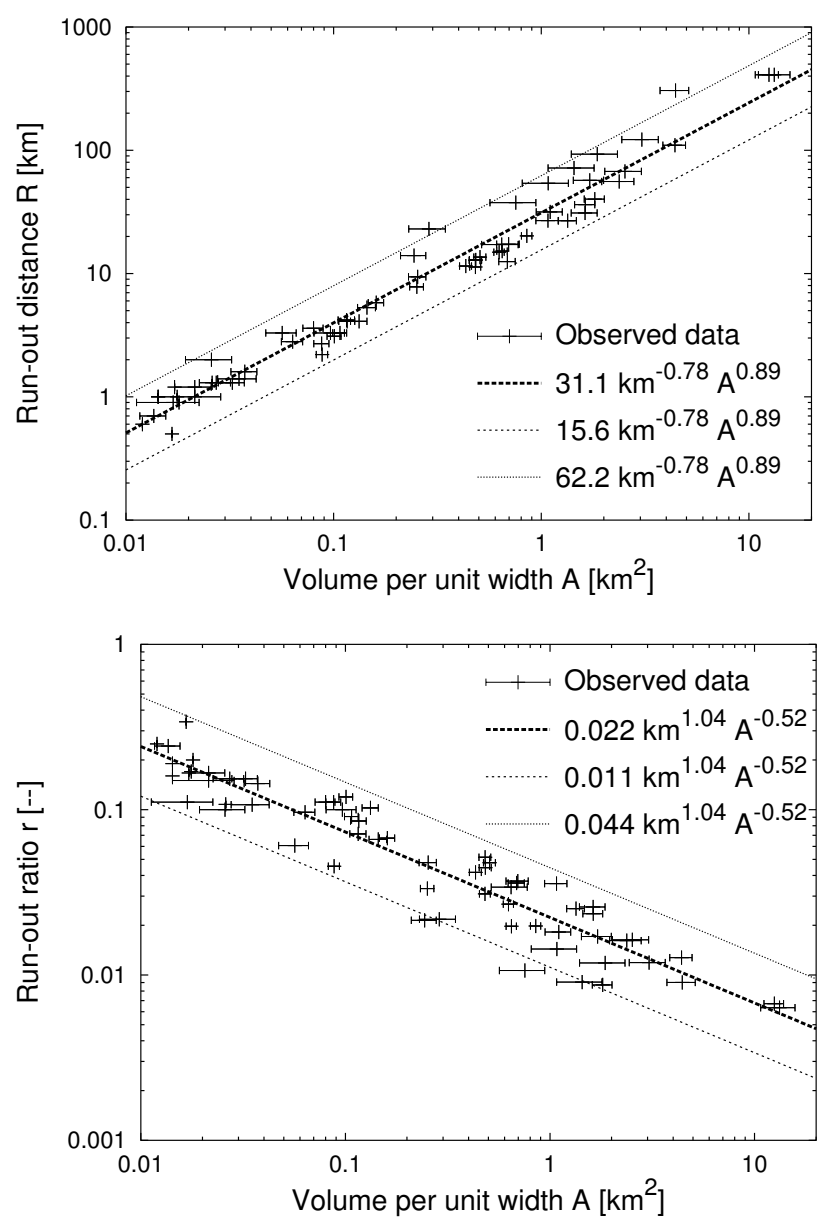

Fig. 6. Scaling behavior of distinct debris flows within the Storegga slide complex: runout distance $R$ vs. release volume per unit width $A$ (top) and runout ratio $r=H / R$ vs. $A$ (bottom) (from Issler et al., 2005).

masses were found to very closely follow the scaling (Issler et al., 2005)

$A \propto V^{2 / 3}, \quad h \propto V^{1 / 3} \propto A^{1 / 2}$

with $h$ the mean height of the released slab. Thus the scalings (1) and (2) can easily be expressed in terms of $V$ if necessary.

Although a large number of submarine slides are known world-wide (Hühnerbach et al., 2004), only very few have been investigated in sufficient detail to allow meaningful comparison with the Storegga data. When the most reliable data are selected and plotted in the same way (Fig. 7), one observes that (i) the Storegga slides are among the least mobile of their kind, (ii) the slides with the most similar material properties, like the Trænadjupet slide north of Storegga, fall on the same regression line as the Storegga slides, and (iii) the envelope defined by the most mobile slides in Fig. 7 has a very similar slope as the Storegga regression line. This last observation is tantalizing, yet very uncertain given the poor knowledge on these slides.

Dade and Huppert (1998) compiled a plot of $1 / r$ as a function of $V$ from different sources, including over 60 terrestrial

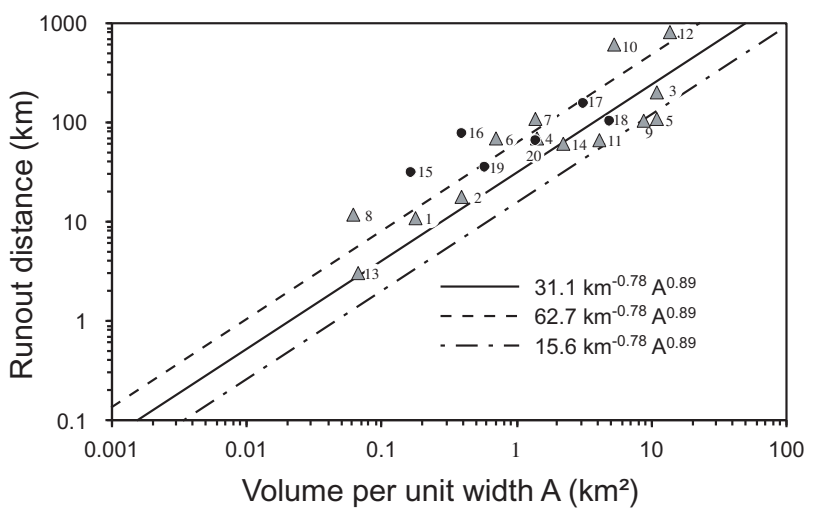

Fig. 7. Selected debris flows from world-wide database. 1: Kidnappers, 2: Kayak Trough, 3: Trænadjupet, 4: East Break East, 5: East Break West, 6: Sur, 7: BIG'95, 8: Afen Slide, 9: Icod, 10: Canary debris flow, 11: El Golfo, 12: Saharan debris flow, 13: New Jersey, 14: Gebra, 15: Isfjorden, 16: Storfjorden, 17: Bear Island, 18: North Sea, 19: Newfoundland f1, 20: Newfoundland f8. The lines indicate the regressions found in Storegga. From (Issler et al., 2005).

and extraterrestrial rockfalls. Situating the submarine slides of Figs. 6 and 7 in that diagram reveals that the very large submarine slides are much more mobile than all rockfalls, where the lowest $r$-values were found to be about 0.03 .

\subsection{Inferences from the scaling behavior}

It is well known that $r$, the tangent of the runout angle, is equal to the friction coefficient for a point mass subject to gravity and Coulomb dry friction only (Scheidegger, 1973), independent of the slope profile. The pronounced dependence $r \propto A^{-1 / 2} \propto h^{-1}$ (Eqs. 2, 3) found in Storegga thus excludes dry friction as the dominant resistive force in these debris flows. One might counter this conclusion by noting that excess pore pressure can drastically reduce the frictional force in a granular mixture - a mechanism that is at the basis of most recent models for subaerial debris flows, e.g. (Iverson and Denlinger, 2001; Denlinger and Iverson, 2001). In the extreme case, the granular material loses all friction and behaves like a Newtonian fluid. The runout ratio will crucially depend on the excess pore pressure and its dissipation rate. While it is possible to fine-tune these parameters so as to reproduce the observed scaling behavior, this does not adequately explain the fairly universal behavior hinted at by the data.

Behavior much closer to the observed one is obtained, however, if the resistive force is assumed to be proportional to the surface area $S$, but independent of the release height and the velocity. Then the resistive force per unit volume becomes inversely proportional to the flow height. Under these conditions, the frictional work is approximately $W \propto R \cdot S$ while the work done by gravity is $\Delta E_{\text {pot. }} \propto H \cdot V$. From this emerges the approximate scaling behavior $r \propto V^{-1 / 3} \propto A^{-1 / 2} \propto h^{-1}$ if account is taken of 
Eq. (3), which implies $S \propto A$.

Such a resistance term is reminiscent of a proposal made by Grigoryan (1979) and of the properties of a Bingham fluid, i.e. a viscous fluid exhibiting yield strength $\tau_{y}$ and viscosity $\mu_{B}$. In the case of simple shear flow, this rheology leads to the following relationship between the shear rate, $\dot{\gamma}$, and the shear stress, $\tau$ :

$\dot{\gamma}= \begin{cases}0 & \text { if }|\tau| \leq \tau_{y}, \\ \operatorname{sgn}(\tau) \frac{1}{\mu_{B}}\left(|\tau|-\tau_{y}\right) & \text { else. }\end{cases}$

For realistic material parameters and flow velocities, we found $\mu_{B} \dot{\gamma} \ll \tau_{y}$ so that $\tau \approx \tau_{y}$ holds, similar to Grigoryan's postulate. However, in the flow of a Bingham fluid the flow thickness decreases steadily because deposited material from the shear layer is left behind, and the resistive force per unit volume increases steadily. When the flow thickness falls below the plug-layer thickness

$h_{p}=\frac{\tau_{y}}{\Delta \rho g \sin \theta}$,

the flow is rapidly stopped (here $\theta$ is the local slope angle and $\Delta \rho$ the density excess of the flowing sediment relative to the ambient water.). Furthermore, the larger the flow the higher the shear rate and thus the influence of the viscous contribution. The scaling relation for a Bingham fluid will therefore deviate from the observed one for large release masses, and it will depend somewhat on the path profile. Numerical simulations, to be discussed in Sect. 4.1, will confirm these conclusions.

\section{Modeling of clay-rich debris flows}

\subsection{Success and limitations of viscoplastic models}

Huang and García (1999) showed that a dynamical model based on the Bingham rheology (Eq. 4) is able to describe the overall flow and spreading of laboratory mudflows quite accurately; only the velocities may be significantly overestimated due to neglect of hydrodynamic drag. A number of studies, e.g. (Major and Pierson, 1992; Parsons et al., 2001) give evidence that the rheological properties of clay-rich slurries at moderate to high shear rates are reasonably well captured by a rheological law of the Herschel-Bulkley type and that even the deviations from the special case of a Bingham fluid (Eq. 4) are not very large. When applying this approach to submarine slides on very gentle slopes, one has to assume that there is at least one weak layer which will remould rapidly and form the failure surface when an external trigger mechanism such as an earthquake strikes.

An alternative modeling approach, developed by Iverson and Denlinger (2001), is based on the Coulomb yield behavior typical of granular materials and invokes persistent excess pore pressure to reduce the bed friction to the low values that must prevail at the release and during the flow. In submarine debris flows along the continental margins, the effective pressure must vanish almost completely for flow to be possible at very low slope angles; then the Coulomb yield behavior effectively becomes irrelevant. If the failing slab is layered, it suffices that the layer forming the glide plane be fluidized; the overlying layers might be almost impermeable and would then help conserve the excess pore pressure created in the structural collapse of the glide plane during the triggering event.

Common to both approaches is the need for an external trigger that leads to the collapse of a weak layer with concomitant remoulding or formation of excess pore pressure. In both cases the bed shear stress becomes much smaller and seemingly independent of the original layer properties. However, clay-rich sediments clearly exhibit yield behavior largely independent of the overburden load and viscosity. It was therefore natural to use a model based on the Bingham rheology for simulating some of the debris flows identified in the Storegga slide complex. For this purpose, the onedimensional thickness-averaged model BING (Imran et al., 2001) was extended with a hydrodynamic drag term. The code solves the overall mass balance and separate equations of motion for the entire mass and the "plug" layer (more precisely: the layer of extensional flow) in a Lagrangean framework. This scheme allows to obtain the evolution of both the plug-layer and total flow thickness. The model assumes the velocity profile to be given by that of a stationary flow under the same conditions and the pressure distribution to be hydrostatic. The equations can be summarized as follows:

$$
\begin{aligned}
\partial_{t} h+\partial_{s} & (h U)=0, \\
D_{t} U_{p}= & \left(U-U_{p}\right) \partial_{s} U_{p}+\tilde{g}_{\|} \\
& \quad-\frac{\operatorname{sgn}(U)}{h_{p} \rho_{d}}\left(\tau_{y}+\tau_{\text {drag }}\right)-\tilde{g}_{\perp} \partial_{s} h,
\end{aligned}
$$

$$
\begin{aligned}
D_{t} U= & \frac{1}{h} \partial_{s}\left(h U^{2}-\frac{7}{5} h U_{p} U+\frac{2}{5} h U_{p}^{2}\right)+\tilde{g}_{\|} \\
& -\frac{\operatorname{sgn}(U)}{h \rho_{d}}\left(\tau_{y}+\frac{2 \mu_{B} U_{p}}{h-h_{p}}+\tau_{\mathrm{drag}}\right)-\tilde{g}_{\perp} \partial_{s} h .
\end{aligned}
$$

Here, $t$ and $s$ denote the time and the coordinate along the flow direction, $h$ is the total flow thickness and $U$ the velocity averaged over $h$, while $h_{p}$ is the thickness of the plug layer, moving with velocity $U_{p} . D_{t} \equiv \partial_{t}+U \partial_{s}$ represents the advective (material) derivative with respect to $U$. The water and debris-flow densities are denoted by $\rho_{w}$ and $\rho_{d}$, respectively. $\tilde{g}_{\|} \equiv g\left(1-\rho_{w} / \rho_{d}\right) \sin \theta(s)$ and $\tilde{g}_{\perp} \equiv g\left(1-\rho_{w} / \rho_{d}\right) \cos \theta(s)$ are the downslope and normal components of the gravitational acceleration, corrected for buoyancy.

The first terms on the right-hand sides of Eqs. (7) and (8) represent advective corrections due to the use of $U$ instead of $U_{p}$ in the advective derivative in Eq. (7) and due to the non-uniform velocity profile in Eq. (8). The second term in both equations is the down-slope gravitational acceleration while the last term is the longitudinal stress gradient due to the assumed hydrostatic pressure distribution. It is, of course, debatable whether this is an adequate approximation to the 
stress distribution in a yield-strength material, but it has been presently adopted for simplicity. Finally, the third term captures the shear stresses at the top $\left(\tau_{\text {drag }}\right)$ and bottom boundary of the plug or total flow layer. Following Huang and García (1998), we assume the steady-state velocity profile to obtain tractable equations; for a Bingham fluid, it is parabolic $\left(\zeta \equiv \frac{z}{h-h_{p}}\right)$ :

$u(z)= \begin{cases}U_{p}\left(1-(1-\zeta)^{2}\right) & \text { if } 0 \leq \zeta \leq 1, \\ U_{p} & \text { if } 1 \leq \zeta .\end{cases}$

The true velocity profile will deviate from this form in general due to inertial effects. In their absence, the thickness of the plug layer is determined by the condition that the shear stress due to the gravitational force on the overburden mass equal the yield strength $\tau_{y}$ (see Eq. 8); the bed shear stress exceeds this value by the viscous contribution $2 \mu_{B} U_{p} /\left(h-h_{p}\right)$, where $\mu_{B}$ is the (Bingham) viscosity.

Precise modeling of the hydrodynamic drag $\tau_{\text {drag }}$ would require the solution of the Navier-Stokes equations around a fast-moving bluff body of variable shape. We propose the following simplified representation:

$\tau_{\mathrm{drag}} \approx \frac{\rho_{w} U_{p}^{2}}{2}\left(C_{P}\left|\partial_{s} h\right| \Theta\left(\operatorname{sgn}\left(U_{p}\right) \partial_{s} h\right)+C_{F}\right)$.

$C_{F}=\mathcal{O}\left(10^{-2}\right)$ and $C_{P}=\mathcal{O}(1)$ are the coefficients of frictional and pressure drag, $\Theta(x)=1$ if $x>0$ and 0 otherwise. This approximation distributes the pressure drag over the "upwind" surface of the flow in proportion to the exposed projected area. Such a term is crucial for limiting the velocities to realistic values but does not strongly influence the runout distance. Finally note that our formulation neglects path curvature effects altogether.

The model is implemented in a code derived from BING (Imran et al., 2001). The initial slab is divided longitudinally into a number of elements with mean height $h_{i}(t=0)$ between the nodes $i-1$ at $s_{i-1}(t=0)$ and $i$ at $s_{i}(t=0)$. Based on the velocities and accelerations at time $t$, the new positions of the nodes at $t+\Delta t$ are calculated. Then the local flow heights are updated so as to assure mass conservation. Finally, the new plug layer thickness is obtained from the new flow thickness and the updated velocities:

$h_{p}=\left(3 U / U_{p}-2\right) h ;$

this relation is a consequence of the steady-state profile (Eq. 9).

In addition to the path geometry, release volume and deposit distribution of the single slides constituting the Storegga slide complex, a significant number of cores are available on which geotechnical tests were performed (Kvalstad et al., 2005). These indicate that the clay material was already normally consolidated to overconsolidated at the time of release. The trigger mechanism must have been such as to completely remould the material already during the release process, at least along the glide plane.

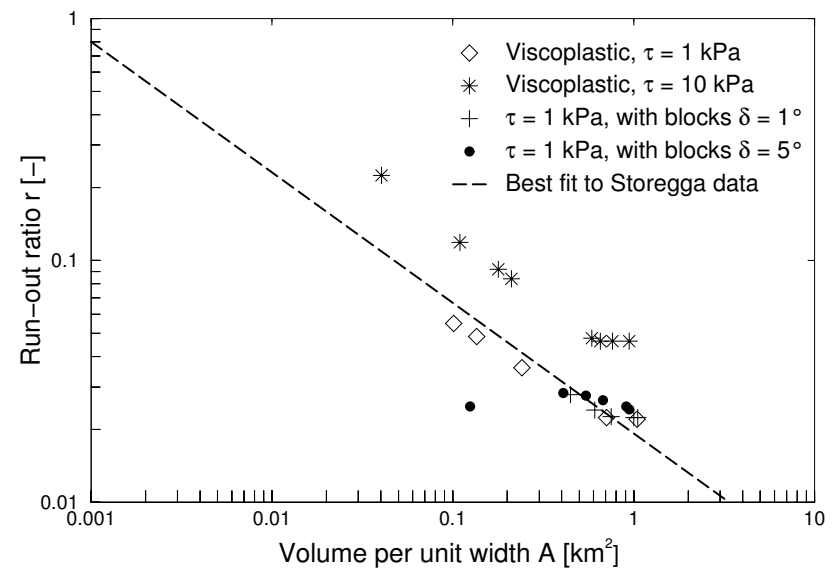

Fig. 8. Scaling behavior of runout ratio with release volume per unit width for the debris-flow models BING (implementing the Bingham rheology with modifications for hydrodynamic drag) and BBING (BING extended for the presence of interspersed large blocks with Coulomb friction characterized by the bed friction angle $\delta$ ). The dashed line is the best-fit power-law relation obtained from the Storegga data. Adapted from (Issler et al., 2005).

Two well-mapped typical slides that affected the area of the Ormen Lange gas field and had runout distances of about $15 \mathrm{~km}$ were simulated with the model (De Blasio et al., 2004a). As in previous model applications, it was found that the Bingham viscosity $\mu_{B}$ had a relatively small influence on the runout distance within bounds compatible with the geotechnical measurements on remoulded clay. Selecting $\tau_{y}$ in the range $8-10 \mathrm{kPa}$ - values compatible with the geotechnical measurements of the unremoulded yield strength if the sensitivity of the clays is taken into account ${ }^{2}-$ the runout distance could be reproduced quite well. However, the deposit distribution inferred from seismic measurements with thickness up to $50 \mathrm{~m}$ in the upper, relatively steep segment of the path (1-3 km from the headwall) and $15-30 \mathrm{~m}$ thick deposits in the lower segment $\left(3-15 \mathrm{~km}\right.$, approx. $\left.1.5^{\circ}\right)$ is in disagreement with the assumed Bingham rheology with constant material properties. According to this, the balance between shear stress and yield strength leads to an approximate deposit thickness $d=h_{p}$, where the plug-layer thickness is given by Eq. (5). An immediate prediction from this equation is that the deposited layer is thin on steep slopes and thick on gentle slopes - in clear disagreement with observations.

Further evidence of the inadequacy of a pure Bingham model for explaining all features of the Storegga slide complex comes from a study of the scaling behavior of the runout ratio with the release volume. On a bathymetric profile

\footnotetext{
${ }^{2}$ Note that these yield strengths are two to three orders of magnitude larger than those of the unconsolidated clay-silt-sand mixtures that were used in laboratory experiments, e.g. by Major and Pierson (1992); Parsons et al. (2001) as well as our group, to test the applicability of the Bingham rheology and to study flow mechanisms. This difference is due to the consolidation and higher clay content of the Storegga sediments and the exponential dependence of yield strength on these parameters.
} 


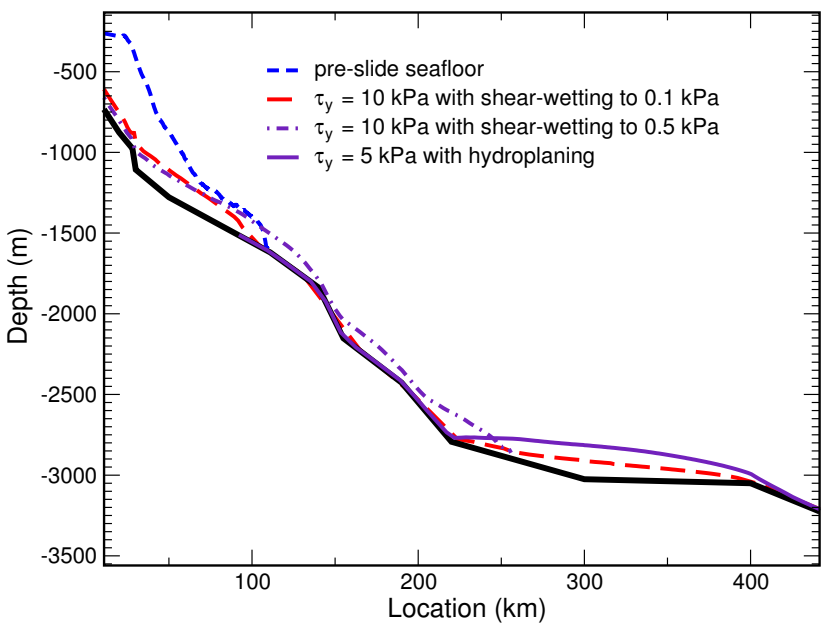

Fig. 9. Final deposit distribution of the first phase of the Storegga debris flow, simulated with W-BING (with hydroplaning) for a yield strength of $5 \mathrm{kPa}$, and R-BING (including shear-wetting from an initial yield strength of $10 \mathrm{kPa}$ to two different residual yield strengths). From (De Blasio et al., 2005).

representative of the Ormen Lange area within the Storegga slide complex, slides with different release volumes were simulated for a variety of yield strengths, Fig. 8 showing the obtained scaling behavior. Up to a release volume per unit width of about $0.3 \mathrm{~km}^{2}$, the exponents found in the statistical study (Issler et al., 2003, 2005) were reproduced very closely, with yield strengths of $6-8 \mathrm{kPa}$ providing the best fit for the runout ratio while values of about $12 \mathrm{kPa}$ gave the best results for the runout distance. However, for larger release volumes, the pure Bingham model predicted almost constant runout distance and runout ratio due to a significant slope break that would require enormous thickness for a Bingham material to flow. Finally, the runout distance of $450 \mathrm{~km}$ for the first and largest phase of the Storegga slide (see Fig. 5) could be reproduced only with unrealistically low values of the yield strength (less than $0.5 \mathrm{kPa}$ ) that further exacerbate the problem with the deposit distribution mentioned above (De Blasio et al., 2003, Fig. 2).

4.2 Simple extensions of BING for hydroplaning and wetting

The purely visco-plastic material behavior in BING was first modified to account for (i) the presence of large slabs of largely intact material inside the sheared, muddy flow, assuming Coulomb frictional behavior for the blocks and progressive abrasion (B-BING), and (ii) the roughly linear increase of the (unremoulded) yield strength with thickness due to consolidation effects (C-BING). As shown by De Blasio et al. (2004a), the pure BING model proved superior to both these extensions because one contribution to the bed shear stress in B-BING and the entire bed shear stress in C-BING scale linearly with the slab thickness. As a consequence, the driving (gravity) and resistive (frictional) forces per unit mass are independent of the total mass and flow depth so that the runout distance scales weakly or not at all with the released mass. Figure 8 illustrates this finding for B-BING in comparison with BING.

In view of the laboratory experiments reported in Sects. 2.3 and 2.4, two further extensions of the basic model were developed: One implements hydroplaning on the basis of the analysis by Harbitz et al. (2003) and is termed WBING (De Blasio et al., 2004b), the other (R-BING) supposes that water is progressively being mixed into the shear layer and reduces the yield strength of the latter from an initial value $\tau_{y, 0}$ to a residual value $\tau_{y, \infty}$ in function of the total accumulated shear $\gamma$ (De Blasio et al., 2003):

$\tau_{y}\left(s\left(s_{0}, t\right), t\right)=\tau_{y, \infty}+\left(\tau_{y, 0}-\tau_{y, \infty}\right) e^{-a \gamma\left(s\left(s_{0}, t\right)\right)}$.

$\gamma\left(s\left(s_{0}, t\right)\right)=\int_{0}^{t} d t^{\prime} \dot{\gamma}\left(s\left(s_{0}, t^{\prime}\right), t^{\prime}\right)$ is integrated over time following the path $s\left(s_{0}, t\right)$ of the material that was at location $s_{0}$ at time $t_{0}$. The so far purely empirical dimensionless parameter $a$ captures the efficiency of shear-wetting; with the value $a=5 \times 10^{-4}$ used in the simulations, the effect is still weak after $20 \mathrm{~km}$, but it becomes quite strong after $50 \mathrm{~km}$. Thus only the runout distances of the few largest individual debris flows that constituted the Storegga slide event are affected. Clearly, this is a heuristic, over-simplifying formulation of a complex process and is only meant to qualitatively capture the idea that water intrusion into the shear layer reduces its strength. A future model needs to describe more precisely at which rate water is mixed into the basal layer and then use appropriate parameterizations of laboratory test results like those of O'Brien and Julien (1988) to determine the temporal evolution of the local yield strength and viscosity.

The hydroplaning model, W-BING, switches between two flow regimes according to a Froude condition for hydroplaning at the front. Its main features are only sketched here, for a more detailed description see (De Blasio et al., 2004b). In the non-hydroplaning regime, W-BING reduces to BING. If hydroplaning occurs, the equations for the debris given in Sect. 4.1 simplify because the shear stress may be assumed to be less than the yield strength and the debris moves essentially as a plug. At the same time a water layer of variable thickness is introduced underneath the debris mass; however, in any given segment of the debris flow, bottom friction reduction due to hydroplaning is assumed effective only if the water layer exceeds a minimum thickness (thought to be of the order of the relevant asperities). Assuming a quadratic velocity profile in the water layer - the solution appropriate to steady uniform Couette flow under a pressure gradient the Navier-Stokes equations can be integrated over the thickness of the flow and written in terms of the local water-layer thickness and the plug velocity. The shear stresses at the bed and the water-debris interface follow from the parabolic velocity profile. In order to close the equations, the dynamic pressure in the layer is assumed to diminish linearly from the stagnation pressure $\frac{1}{2} \rho_{w} U^{2}$ at the snout to 0 at the rear end of the debris flow.

Figure 9 reports the results of simulations of the first phase of the Storegga slide, carried out with W-BING and R-BING. 


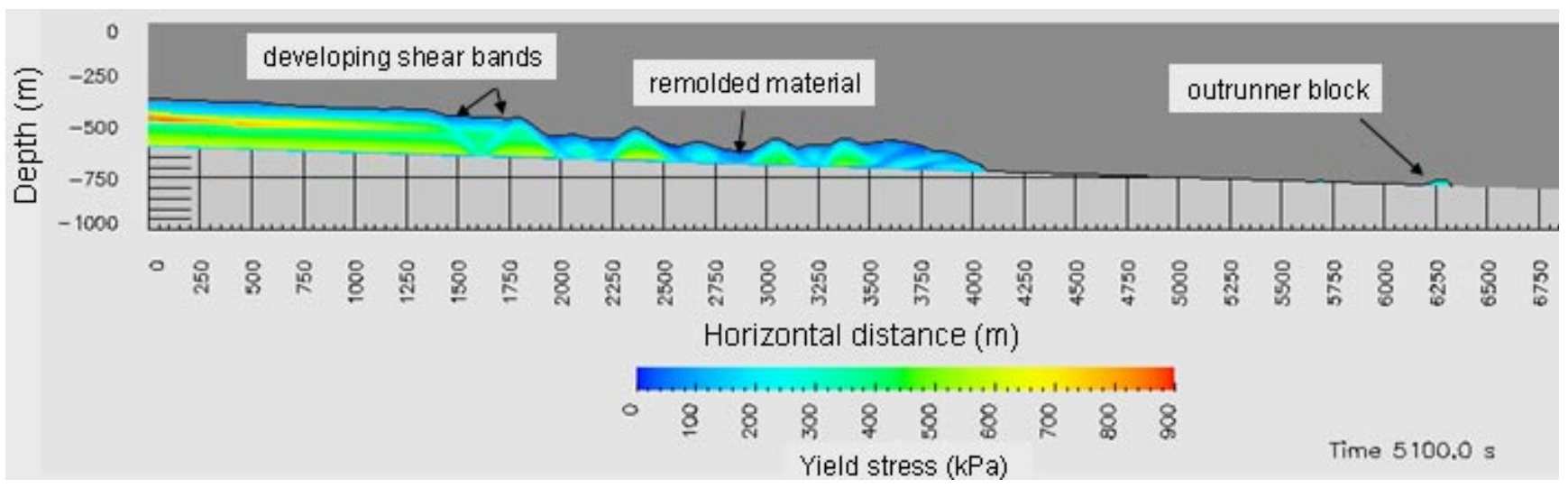

Fig. 10. Numerical simulations illustrating retrogressive, back-stepping behavior. Shown is the yield stress at an intermediate time (1 h $25 \mathrm{~min}$ ). The simulations were performed using the CFX4.4 flow-solver from ANSYS.

Simulations with BING (not shown) using a realistic remoulded yield strength reached runout distances of less than $200 \mathrm{~km}$. With R-BING, it had to be assumed that the residual yield strength was two orders of magnitude smaller than the initial remoulded yield strength. As mentioned above, with appropriate values of the efficiency parameter $a$, the runout distance of the phase 1 slide could be reproduced without upsetting the good match of the runout distances obtained for the small slides with the same parameter values.

The runout distance of phase 1 could also easily be obtained with hydroplaning (W-BING). The different mechanisms in hydroplaning and shear-wetting manifest themselves in characteristic deposit distributions. Hydroplaning decouples the flowing debris from the bed so that very little or no mass is deposited while hydroplaning is on-going; a very thick deposit is formed in the abyssal plain (Fig. 9). In R-BING, the moving slab deposits a substantial amount of mass in a rather thick layer on the relatively steep slope just after release due to the still high yield strength; the distal deposits are accordingly thinner. This is in (at least qualitative) agreement with the observations from Storegga.

The peak acceleration and velocity predicted by numerical simulations are decisive input parameters for the modeling of slide-generated tsunamis. The initial acceleration of the slide mass is relatively insensitive to lubrication effects that set in at high velocities (hydroplaning) or grow with the accumulated shear (shear-wetting). Furthermore, BING, R-BING and W-BING all indicated peak velocities (at the front) between 50 and $60 \mathrm{~m} \mathrm{~s}^{-1}$ for phase 1 of the Storegga slide (Fig. 5); the velocity evolution differed significantly between models, though. Among the many recent papers that investigate the connection between submarine debris flows and tsunami generation, (Bondevik et al., 2005; Haugen et al., 2005; Løvholt et al., 2005) are particularly relevant to our simulations of the Storegga phase 1 debris flow. They use the slide mass and geometry from the Ormen Lange investigations and the measured runup heights of the Storegga tsunami along the Norwegian coast, in Scotland, on the Shetland and the Færøe Islands to infer the most likely center-of-mass acceleration and peak velocity of the slide. Their assumptions concerning the initial conditions (retrogressive slide comprising all phases, with many relatively small chunks released in short intervals) differ from our assumption that the entire phase 1 mass was released simultaneously. Nevertheless, our simulated center-of-mass velocity agrees quite well with their result of $25-30 \mathrm{~m} \mathrm{~s}^{-1}$. If it is assumed that the entire mass was released at once, a center-ofmass velocity of only $20 \mathrm{~m} \mathrm{~s}^{-1}$ reproduces the inferred runup heights. We have not simulated this specific scenario, but clearly such a "low" velocity would not be compatible with our models of the flow mechanisms.

\subsection{Detailed modeling of initial fragmentation and frontal behavior}

As seen in the example of the Storegga slide, the transition from an intact seafloor with considerable strength to a flowing mass with an enormous runout distance is an unresolved topic. However, the understanding of the in situ conditions and mechanisms that could generate such slides at low average inclinations (as is the case in Storegga) is of vital importance for risk assessment. Two aspects are of special interest: First, how does a sediment slab disintegrate? Second, what are the conditions for hydroplaning to occur?

The morphology of the Storegga slide deposits and highresolution seismic profiles indicate a slide pattern that is similar to slides of marine quick-clay typical of onshore areas in Scandinavia and Canada. A series of slide terraces consisting of nearly intact slide blocks and graben structures point towards a retrogressive slide process similar to quick-clay slide development.

Numerical simulations can reproduce this retrogressive, back-stepping behavior (Gauer et al., 2005). Our code incorporates a rheological model based on a Bingham fluid with a history/strain dependent yield strength and consistency; the initial conditions prescribe a weak layer that eventually becomes the glide plane. The slide and the ambient water are modeled by a two-phase model approach. For both phases 
the continuity and momentum equations are solved. The slide model uses an effective viscosity

$\mu_{\text {eff. }}=\frac{Y}{\dot{\gamma}}+K$,

where the undrained yield stress, $Y$, and the consistency, $K$, are assumed to be functions of the strain history so as to account for remoulding. $\dot{\gamma}$ is the equivalent shear rate. The remoulding of a sediment parcel is expressed by ${ }^{3}$

$D_{t} Y=C \min \left(Y_{\infty}-Y\right) \dot{\gamma}$.

$Y_{\infty}$ denotes the residual remoulded strength, $C$ the remoulding coefficient, and $D_{t} \equiv \partial_{t}+\mathbf{u} \cdot \nabla$ indicates the material differentiation in time (Eq. 14 is the differential form of Eq. 12). The integral of the equivalent shear rate over time serves as a measure for the remoulding of the specific sediment volume. Hence, Eq. (14) predicts a decrease in the yield strength with straining/remoulding as long as the actual yield strength is larger than the residual strength. As the material weakens on shear, further shear takes place preferentially in zones which have previously been sheared. As a consequence, failure can occur with shear being confined to a few failure zones and can leave blocks basically intact. This effect is clearly seen in Fig. 10 and agrees with the morphological observations at the present-day headwall of the Storegga slide. The pure Bingham as well as Herschel-Bulkley model are unable to capture this observed behavior.

However, the remoulded strength is still too high to explain the observed long runout distances. As discussed in Sect. 4.2 in the context of thickness-averaged (one-dimensional) models, the frontal behavior of the slide might play an important role because it may begin to hydroplane. The two-phase approach of the numerical model allows to investigate the interaction between the slide and the ambient water more closely. The back-calculations of laboratory experiments (see Fig. 11) show the development of a high-pressure wedge of ambient water underneath the slide and of underpressure along its upper surface. Also a velocity decrease from the head to the tail of the slide, which leads to stretching of the slide mass, can be observed. The effects of the intruding water on the material properties, e.g. the softening of the contact layer between slide and bed surface through strain-induced wetting, are not included in this model.

\section{Discussion and conclusions}

Are the laboratory experiments a good model of natural subaqueous debris flows? Our approach to studying the important open questions of submarine debris flows relies heavily

\footnotetext{
${ }^{3}$ Despite the appearance of $\dot{\gamma}$ in Eq. (14), we are not assuming a shear-rate dependent yield strength. The decisive factor is the "accumulated shear" that describes how often the bonds between (clay) particles were broken and how many cracks have formed through which water can penetrate.
}

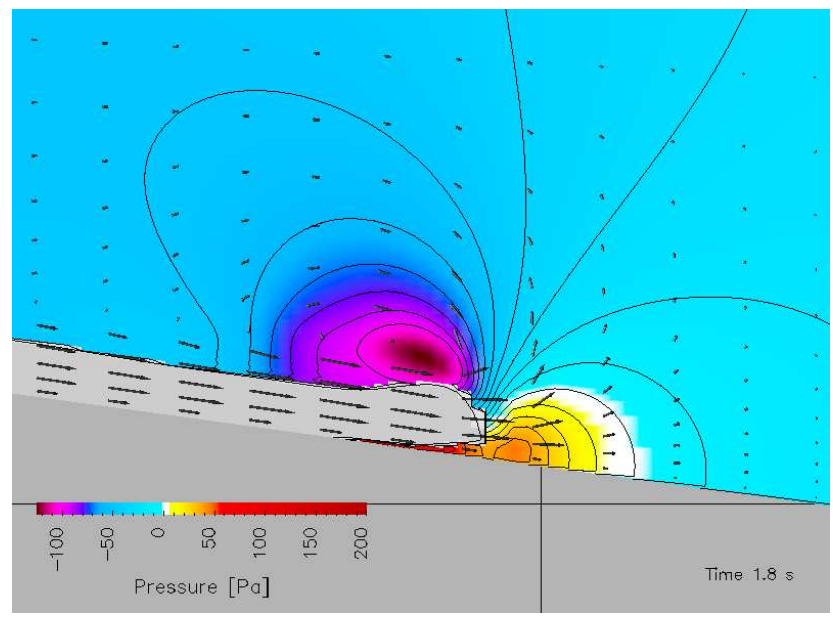

Fig. 11. Back-calculation of laboratory experiments, snapshot at $1.8 \mathrm{~s}$ after release. Pressure field (color shaded), isobars (black lines) and velocity field (arrows) around the head of a slide (simulations were performed using the ANSYS CFX4.4 flow solver).

on process studies in laboratory flows. Thus, before assessing what conclusions can be drawn from our study, the question of similarity between natural and laboratory flows needs to be discussed. The geometric scaling is distorted, i.e. our model slope is much steeper than typical continental margins. Horizontal $(L)$ and vertical $(H)$ lenghts scale between model $(m)$ and prototype $(p)$ quantities as

$L^{(m)}=\lambda_{h} L^{(p)}, \quad H^{(m)}=\lambda_{v} H^{(p)}$.

In our laboratory setting, $\quad \lambda_{v}=\mathcal{O}\left(10^{-3}-10^{-2}\right)$ and $\lambda_{h}=\mathcal{O}\left(10^{-5}-10^{-3}\right)$. To good approximation, the debris and water densities match between the model and the prototype. Hence, one condition for dynamic similarity is that the inertial and gravitational forces be in the same proportion in the model and the prototype, as expressed in the equality of the densimetric Froude numbers $\operatorname{Fr}_{d}^{(m, p)}=U^{(m, p)}\left(\tilde{g}^{(m, p)} \cos \theta^{(m, p)}\right)^{-1 / 2}$. This leads to the following scaling of the slope-parallel velocity $U$, the stresses $\tau$ and the time $T$ :

$U^{(m)}=\lambda_{v}^{1 / 2} U^{(p)}$,

$\tau^{(m)}=\lambda_{v} \tau^{(p)}$,

$T^{(m)}=\lambda_{h} \lambda_{v}^{-1 / 2} T^{(p)}$.

The yield strength, representing the dominant contribution to the resistive forces, should scale with $\lambda_{v}$ like the stresses and typically be two to three orders of magnitude smaller in the laboratory than in Nature. This may easily be realized at the start of an experiment, but we do not know at this point whether the shear-wetting we have observed respects this stress-scaling factor or not. Significant similarity violation occurs in the thickness of the plug layer because $\sin \theta^{(m)} \approx\left(\lambda_{v} / \lambda_{h}\right) \sin \theta^{(p)}$, hence according to Eq. (5) 


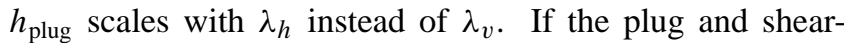
layer thickness respected the vertical scaling relation, equal Reynolds number inside the flowing sediment and similarity of stresses could be achieved by choosing the model viscosity as $v^{(m)}=\lambda_{v}^{3 / 2} v^{(p)}$, but the distorted geometric scaling precludes exact dynamical similarity.

The basic scale of hydrodynamic stresses, being proportional to $U^{2}$, respects Eq. (17). However, the very high Reynolds numbers of the recirculating flow of ambient water around natural debris flows cannot be matched in the laboratory because the viscosities of the model and prototype fluid are the same. In particular the transition to turbulence in the boundary layer will occur at the snout of a natural debris flow but only in the rear of a typical laboratory flow. This influences the drag coefficient and probably also the rate of turbidity-current formation.

In conclusion, significant similarity violations cannot be avoided in this kind of laboratory experiments. Without geometric distortion, similarity inside the flowing sediment could be achieved with respect to the Froude and Reynolds numbers if a slurry of low yield strength and very low viscosity could be produced, but problems arise with the flow of the ambient water, and further problems are to be expected with respect to particle settling and the shear-wetting behavior of the slurry. The laboratory experiments are therefore to be used as guidance in the study of particular processes; a more detailed similarity analysis will be needed to estimate the rate at which shear-wetting might occur in natural subaqueous debris flows.

Has the mystery of the long runout distances finally been solved? Our experiments directly show that the mobility of clay-rich subaqueous debris flows in the laboratory may be drastically enhanced due to hydroplaning and shear-wetting. How do these mechanisms operate in full-scale flows? Are there other likely mechanisms to explain the observed extremely long runout distances?

The condition for the onset of hydroplaning is the development of a sufficient lift force at the head of the flow to overcome its weight. This balance is characterized by the densimetric Froude number, and large submarine debris flows are expected to exceed the threshold Froude number (approx. 0.4 ), as do many laboratory flows. Indeed, simulations of the startup phase of submarine debris flows with BING (De Blasio et al., 2004a) showed that non-hydroplaning flows of sufficient size quickly reach rather high velocities that allow hydroplaning to begin; this is confirmed by the twodimensional numerical simulations presented in Sect. 4.3. An implicit assumption is that the lubricating water layer underneath the head of the flow persists over a substantial portion of the flow duration. As Mohrig et al. (1998) discussed and our measurements verified, this condition is fulfilled in moderately and strongly coherent laboratory flows; the same arguments should apply even more to clay-rich fullscale flows. We conclude that hydroplaning should be an important factor in the dynamics of many submarine debris flows.
If the head begins to hydroplane, stretching of the neck is inevitable and leads to the formation of cracks that will allow water to penetrate into the flowing material. It is well established that already small additional quantities of water drastically reduce the strength of remoulded clay (Coussot, 1997). We are not yet able to quantify these effects and understand their scaling behavior, but we consider it very likely that stretching and shear-wetting play an important role in explaining the long runout distances of natural subaqueous debris flows. Particle-tracking analysis of larger samples from our videos and a detailed study of the velocity profiles may give more insight into the shear-wetting process and suggest dedicated further experiments.

High excessive pore pressure generated during slide release could also explain very long runout. Our experimental procedure is not suitable for studying this mechanism. We note that the effective pressure under the head of all our laboratory flows, from strongly to weakly coherent, was close to zero; this was, however, due to the external pressure gradient in the flow of the ambient water: In moderately and strongly coherent flows, this pressure gradient leads to hydroplaning. In contrast, bulk transformation of the head into a turbulent suspension occurs in weakly coherent flows. If the triggering mechanism itself was responsible for fluidization, one would expect small flows to also have excessively long runout distances. However, this is not verified by the scaling relation $r(A)$ (Eq. 2) obtained in the Storegga slide complex.

What role do submarine debris flows play in the oceans? There is now ample evidence that debris flows are the major agent in mass-wasting on glacier-influenced continental margins. Turbidity currents - sometimes with runout distances approaching $10^{3} \mathrm{~km}-$ are associated with major slides like Storegga or Grand Banks, but the mass of the turbidites does not seem to exceed $10 \%$ of the mass of the parent clay-rich debris flows. This is in line with the low suspension rates found by (Mohrig and Marr, 2003).

Our work has not so far considered the formation of turbidity currents from debris flows in any detail, nor have we examined the depositional patterns of sand-rich debris flows (and in particular the question under which conditions the clay and sand in the originally released sediment get separated). However, our observations confirm the findings of Mohrig and Marr (2003) that the head of sand-rich, weakly coherent flows undergoes a gradual transition from dense, laminar flow to more dilute, turbulent flow. Our experimental approach combining measurements of total pressure and pore pressure with analysis of tracer-particle tracks in highspeed video recordings appears well suited to investigations of the density evolution of the head and measurements of the profiles of the mean and fluctuation velocity. These data will allow a deeper understanding of the factors that govern the dynamics of such flows and the spatial structure of their deposits, and they should be very useful for validating numerical models such as those presented by Tinterri et al. (2003) under controlled laboratory conditions. 
Acknowledgements. Work on this paper has been funded by the Norwegian Research Council through the International Centre for Geohazards as part of ICG Project 9, "Slide dynamics and mechanics of disintegration". We wish to thank our colleagues G. Parker, J. Marr, K. Høeg, J. P. Nystuen, L. Engvik, T. J. Kvalstad, J. Locat, H. Haflidason and A. Solheim who have contributed to our research through many insightful suggestions, enjoyable discussions, encouraging and constructive paper reviews. A. Moe helped diligently with the tedious, semi-manual particle-tracking. We are equally grateful for the hospitality we experienced at the St. Anthony Falls Laboratory, University of Minnesota. A. Armigliato and J. Parsons provided detailed and thoughtful criticism of the manuscript and so helped to improve it significantly. This is publication no. 90 from the International Centre for Geohazards.

Edited by: S. Tinti

Reviewed by: A. Armigliato and J. Parsons

\section{References}

Bondevik, S., Løvholt, F., Harbitz, C., Mangerud, J., Dawson, A., and Svendsen, J. I.: The Storegga Slide tsunami-comparing field observations with numerical simulations, Mar. Petrol. Geol., 22, 195-208, doi:10.1016/j.marpetgeo.2004.10.003, 2005.

Bugge, T., Befring, S., Belderson, R. H., Eidvin, T., Jansen, E., Kenyons, N. H., Holtedahl, H., and Sejrup, H. P.: A giant threestage submarine slide off Norway, Geo Mar. Lett., 7, 191-198, 1987.

Bugge, T.: Submarine slides on the Norwegian continental margin, with special emphasis on the Storegga area, Publ. Cont. Shelf Inst. 110, Institutt for Kontinentalsokkelundersøkelser, Trondheim, Norway, 1983.

Coussot, P.: Mudflow Rheology and Dynamics, A. A. Balkema, Rotterdam, Netherlands, 1997.

Dade, W. B. and Huppert, H. E.: Long-runout rockfalls, Geol., 26, 803-806, 1998.

Denlinger, R. P. and Iverson, R. M.: Flow of variably fluidized granular masses across three-dimensional terrain, 2. Numerical predictions and experimental tests, J. Geophys. Res., 106, 553-566, 2001.

De Blasio, F. V., Issler, D., Elverhøi, A., Harbitz, C. B., Ilstad, T., Bryn, P., Lien, R., and Løvholt, F.: Dynamics, velocity and runout of the giant Storegga slide, in: Submarine Mass Movements and Their Consequences, edited by: Locat, J. and Mienert, J., Adv. Natural Technol. Hazards Res., 19, 223-230, 2003.

De Blasio, F. V., Elverhøi, A., Issler, D., Harbitz, C. B., Bryn, P., and Lien, R.: Flow models of natural debris flows originating from overconsolidated clay materials, Marine Geol., 213, 439455, doi:10.1016/j.margeo.2004.10.018, 2004a.

De Blasio, F. V., Engvik, L., Harbitz, C. B., and Elverhøi, A.: Hydroplaning and submarine debris flows, J. Geophys. Res., 109, doi:10.1029/2002JC001 714, 2004b.

De Blasio, F. V., Elverhøi, A., Issler, D., Harbitz, C. B., Bryn, P., and Lien, R.: On the dynamics of clay rich gravity mass flows - the giant Storegga Slide, Norway, Marine Petrol. Geol., 22, 179-186, doi:10.1016/j.marpetgeo.2004.10.014, 2005.

Drago, M.: A coupled debris flow-turbidity current model, Ocean Eng., 29, 1769-1780, 2002.

Elverhøi, A., De Blasio, F. V., Butt, F. A., Issler, D., Harbitz, C. B., Engvik, L., Solheim, A., and Marr, J.: Submarine mass-wasting on glacially influenced continental slopes - processes and dy- namics, in Glacier-Influenced Sedimentation on High-Latitude Continental Margins, edited by J. A. Dowdeswell and C. Ó Cofaigh, Geological Society of London, London, UK, 73-87, 2002.

Gauer, P., Kvalstad, T. J., Forsberg, C. F., Bryn, P., and Berg, K.: The last phase of the Storegga Slide: simulation of retrogressive slide dynamics and comparison with slide-scar morphology, Marine Petrol. Geol., 22, 171-178, doi:10.1016/j.marpetgeo.2004.10.004, 2005.

Grigoryan, S. S.: A new law of friction and mechanism for largescale avalanches and landslides, Sov. Phys. Dokl., 24, 110-111, 1979.

Haflidason, H., Sejrup, H. P., Nygård, A., Mienert, J., Bryn, P., Lien, R., Forsberg, C. F., Berg, K., and Masson, D.: The Storegga Slide: architecture, geometry and slide development, Marine Geol., 213, 201-234, doi:10.1016/j.margeo.2004.10.007, 2004.

Hampton, M.: Subaqueous debris flow and generation of turbidity currents, Ph.D. thesis, Stanford University, Stanford, California, USA, 1970.

Hampton, M., Lee, H. J., and Locat, J.: Submarine landslides, Rev. Geophys., 34, 33-59, 1996.

Hampton, M.: The role of subaqueous debris flow in generating turbidity currents, Sed. Petrology, 42, 775-793, 1972.

Harbitz, C. B., Parker, G., Elverhøi, A., Marr, J. G., Mohrig, D., and Harff, P. A.: Hydroplaning of subaqueous debris flows and glide blocks: Analytical solutions and discussion, J. Geophys. Res., 108, 2349-2366, 2003.

Haugen, K. B., Løvholt, F., and Harbitz, C. B.: Fundamental mechanisms for tsunami generation by submarine mass flows in idealised geometries, Marine Petrol. Geol., 22, 209-217, doi:10.1016/j.marpetgeo.2004.10.016, 2005.

Heezen, B. C. and Ewing, M.: Turbidity currents and submarine slumps, and the 1929 Grand Banks earthquake, Am. J. Sci., 250, 849-873, 1952.

Huang, X. and García, M. H.: A Herschel-Bulkley model for mud flow down a slope, J. Fluid Mech., 374, 305-333, 1998.

Huang, X. and García, M. H.: Modeling of non-hydroplaning mud flows on continental slopes, Marine Geol., 154, 132-142, 1999.

Hühnerbach, V., Masson, D. G., and COSTA project partners: An analysis of submarine landslide dynamics and processes in the North Atlantic, Marine Geol., 213, 343-362, 2004.

Ilstad, T., De Blasio, F. V., Elverhøi, A., Harbitz, C. B., Engvik, L., Longva, O., and Marr, J. G.: On the frontal dynamics and morphology of submarine debris flows, Marine Geol., 213, 481497, doi:10.1016/j.margeo.2004.10.020, 2004a.

Ilstad, T., Elverhøi, A., Issler, D., and Marr, J.: Subaqueous debris flow behaviour and its dependence on the sand/clay ratio: a laboratory study using particle tracking, Marine Geol., 213, 415-438, doi:10.1016/j.margeo.2004.10.017, 2004b.

Ilstad, T., Marr, J. G., Elverhøi, A., and Harbitz, C. B.: Laboratory studies of subaqueous debris flows by measurements of pore-fluid pressure and total stress, Marine Geol., 213, 403-414, doi:10.1016/j.margeo.2004.10.016, 2004c.

Imran, J., Harff, P., and Parker, G.: A numerical model of submarine debris flows with graphical user interface, Computers Geosci., 274, 717-729, 2001.

Issler, D., De Blasio, F. V., Elverhøi, A., Ilstad, T., Haflidason, H., Bryn, P., and Lien, R.: Issues in the assessment of gravity mass flow hazard in the Storegga area off the western Norwegian coast, in: Submarine Mass Movements and Their Consequences, edited by: Locat, J. and Mienert, J., Adv. Natural Technol. Hazards Res., 19, 231-238, 2003.

Issler, D., De Blasio, F. V., Elverhøi, A., Bryn, P., and 
Lien, R.: Scaling behaviour of clay-rich submarine debris flows, J. Marine Petrol. Geol., 22, 187-194, doi:10.1016/j.marpetgeo.2004.10.015, 2005.

Iverson, R. M. and Denlinger, R. P.: Flow of variably fluidized granular masses across three-dimensional terrain, 1. Coulomb mixture theory, J. Geophys. Res., 106, 537-552, 2001.

Kuenen, P. H. and Migliorini, C. I.: Turbidity currents as a source of graded bedding, J. Geol., 58, 91-127, 1950.

Kuenen, P. H.: Experiments in connection with Daly's hypothesis on the formation of submarine canyons, Leidse Geol. Mededel., 8, 327-335, 1937.

Kvalstad, T. J., Nadim, F., Kaynia, A., Mokkelbost, K. H., and Bryn, P.: Soil conditions and slope stability in the Ormen Lange area, Marine Petrol. Geol., 22, 299-310, doi:10.1016/j.marpetgeo.2004.10.021, 2005.

Løvholt, F., Harbitz, C. B., and Haugen, K. B.: A parametric study of tsunamis generated by submarine slides in the Ormen Lange/Storegga area off western Norway, Marine Petrol. Geol., 22, 219-231, doi:10.1016/j.marpetgeo.2004.10.017, 2005.

Major, J. J. and Pierson, T. C.: Debris flow rheology: experimental analysis of fine-grained slurries, Water Resources Res., 28, 841857, 1992.

Marr, J. G., Harff, P. A., Shanmugam, G., and Parker, G.: Experiments on subaqueous sandy gravity flows: The role of clay and water content in flow dynamics and depositional structures, GSA Bull., 113, 1377-1386, 2001.
Mohrig, D. and Marr, J. G.: Constraining the efficiency of turbidity current generation from submarine debris flows and slides using laboratory experiments, Marine Petrol. Geol., 20, 883-899, doi:10.1016/j.marpetgeo.2003.03.002, 2003.

Mohrig, D., Whipple, K. X., Hondzo, M., Ellis, C., and Parker, G.: Hydroplaning of subaqueous debris flows, GSA Bull., 110, 387394, 1998.

Mohrig, D., Elverhøi, A., and Parker, G.: Experiments on the relative mobility of muddy subaqueous and subaerial debris flows, and their capacity to remobilize antecedent deposits, Marine. Geol., 154, 117-129, 1999.

O'Brien, J. S. and Julien, P. Y.: Laboratory analysis of mudflow properties, J. Hydrol. Eng., 114, 877-887, 1988.

Parsons, J. D., Whipple, K. X., and Simoni, A.: Experimental study of the grain-flow, fluid-mud transition in debris flows, J. Geol., 109, 427-447, 2001.

Scheidegger, A. E.: On the prediction of the reach and velocity of catastrophic rockfalls, Rock Mech., 5, 231-236, 1973.

Tinterri, R., Drago, M., Consonni, A., Davoli, G., and Mutti, E.: Modelling subaqueous bipartite sediment gravity flows on the basis of outcrop constraints: first results, Marine Petrol. Geol., 20, 911-933; doi:10.1016/j.marpetgeo.2003.03.003, 2003. 